\title{
Starch-mediated synthesis of mono- and bimetallic silver/gold nanoparticles as antimicrobial and anticancer agents
}

This article was published in the following Dove Medical Press journal: International Journal of Nanomedicine

\author{
Diana Lomelí-Marroquín' \\ David Medina Cruz 2,3 \\ Alfonso Nieto-Argüello' \\ Ada Vernet Crua ${ }^{2,3}$ \\ Junjiang Chen ${ }^{2,3}$ \\ Alejandro Torres-Castro ${ }^{4}$ \\ Thomas J Webster ${ }^{2,3}$ \\ Jorge L Cholula-Díaz'
}

'School of Engineering and Sciences, Tecnologico de Monterrey, Monterrey, NL 64849, Mexico; ${ }^{2}$ Department of Chemical Engineering, Northeastern University, Boston, MA 02115 , USA; ${ }^{3}$ Nanomedicine Science and Technology Center, Northeastern University, Boston, MA 02II5, USA; ${ }^{4}$ Faculty School of Mechanical and Electrical Engineering (FIME), Autonomous University of Nuevo Leon (UANL), San Nicolás de los Garza, NL 6645I, Mexico
Background and aim: Bimetallic silver/gold nanosystems are expected to significantly improve therapeutic efficacy compared to their monometallic counterparts by maintaining the general biocompatibility of gold nanoparticles (AuNPs) while, at the same time, decreasing the relatively high toxicity of silver nanoparticles (AgNPs) toward healthy human cells Thus, the aim of this research was to establish a highly reproducible one-pot green synthesis of colloidal AuNPs and bimetallic Ag/Au alloy nanoparticles (NPs; Ag/AuNPs) using starch as reducing and capping agent.

Methods: The optical properties, high reproducibility, stability and particle size distribution of the colloidal NPs were analyzed by ultraviolet (UV)-visible spectroscopy, dynamic light scattering (DLS) and $\zeta$-potential. The presence of starch as capping agent was determined by Fourier transform infrared (FT-IR) spectroscopy. The structural properties were studied by X-ray diffraction (XRD). Transmission electron microscopy (TEM) imaging was done to determine the morphology and size of the nanostructures. The chemical composition of the nanomaterials was determined by energy-dispersive X-ray spectroscopy (EDS) and inductively coupled plasma mass spectrometry (ICP-MS) analysis. To further study the biomedical applications of the synthesized nanostructures, antibacterial studies against multidrug-resistant (MDR) Escherichia coli and methicillin-resistant Staphylococcus aureus (MRSA) were conducted. In addition, the NPs were added to the growth media of human dermal fibroblast (HDF) and human melanoma cells to show their cytocompatibility and cytotoxicity, respectively, over a 3-day experiment. Results: UV-visible spectroscopy confirmed the highly reproducible green synthesis of colloidal AuNPs and Ag/AuNPs. The NPs showed a face-centered cubic crystal structure and an icosahedral shape with mean particle sizes of 28.5 and $9.7 \mathrm{~nm}$ for AuNPs and Ag/AuNPs, respectively. The antibacterial studies of the NPs against antibiotic-resistant bacterial strains presented a dose-dependent antimicrobial behavior. Furthermore, the NPs showed cytocompatibility towards HDF, but a dose-dependent anticancer effect was found when human melanoma cells were grown in presence of different NP concentrations for 72 hours.

Conclusion: In this study, mono- and bimetallic NPs were synthesized for the first time using a highly reproducible, environmentally friendly, cost-effective and quick method and were successfully characterized and tested for several anti-infection and anticancer biomedical applications. Keywords: green nanotechnology, noble metal alloy nanoparticles, nanomedicine, physicochemical properties

\section{Introduction}

In 1928, Sir Alexander Fleming changed modern medicine with the discovery of penicillin. ${ }^{1}$ However, in 1945, in his Nobel Prize acceptance speech, he delivered a few notes that predicted our present concern with the overuse of antibiotics, which
Correspondence: Jorge L Cholula-Díaz School of Engineering and Sciences, Tecnologico de Monterrey, Av. Eugenio Garza Sada 250I Sur, Col. Tecnológico, Monterrey, NL 64849, Mexico Tel +528183582000 Email jorgeluis.cholula@tec.mx

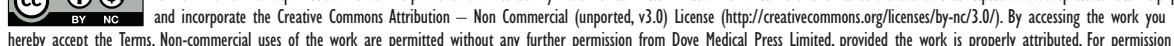

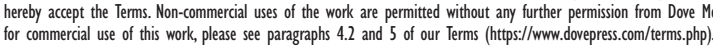


we are now beginning to realize. Antimicrobial resistance (AMR) to antibiotics is a phenomenon that happens when pathogens (such as bacteria, fungi or viruses) develop the ability to defeat the drugs that were designed to inhibit or kill them. ${ }^{2,3}$ AMR can happen naturally, for instance, as a result of interactions and competition between bacterial strains or can be triggered by human beings, through both the misuse and/or overuse of antibiotics. ${ }^{4}$ Human-induced AMR causes infections today that were easily treated in the past and now require extended hospital stays and/or follow-up doctor visits as well as costly and toxic alternatives. ${ }^{5}$ Therefore, humankind now lives in the post-antibiotic era, where each year in the United States, at least 2 million people are infected with antibiotic-resistant bacteria and at least 23,000 die as a result. ${ }^{6}$ Data from the Centers for Disease Control and Prevention (CDC) show that, by 2050, AMR infections will kill more people than all other known diseases together, including cancer. ${ }^{6}$

Therefore, a solution far away from the current use of antibiotics is needed now, and nanotechnology appears as a potential answer. Born together with microelectronics, biotechnology and molecular biology in the 1990s, nanotechnology was soon enough applied to medicine with the appearance of a new field: nanomedicine. Different nanomaterials were used for biomedical applications: from gold nanoparticles (AuNPs) that can fight bacterial infections ${ }^{7,8}$ to magnetic nanostructures that can destroy the most aggressive types of cancers, ${ }^{9,10}$ together with nanomaterials that can enhance the proliferation of cells for wound healing ${ }^{11}$ or even deliver drugs inside the human body. ${ }^{12}$ A new field was created with a broad horizon ahead.

In recent years, the application of noble metal nanoparticles (NPs), mainly AuNPs and silver NPs (AgNPs), has received considerable attention due to their likely use in diagnostic and therapeutic applications. ${ }^{13}$ Although the potent antimicrobial effect and cytotoxicity of AgNPs have been extensively documented, ${ }^{14,15}$ AuNPs are considered more biocompatible for a wide range of particle sizes and concentrations. ${ }^{16}$ These excellent characteristics add to welltunable plasmonic properties of Au-based nanostructures that have been extensively explored in biomedical applications such as biosensing, X-ray computed tomography contrast and photothermal therapy. ${ }^{17}$ Regarding the bimetallic Ag/Au alloy NPs, it is possible to systematically vary their physicochemical properties (especially their optical properties) as a function of the NP composition. ${ }^{18}$

Traditional synthetic chemistry has been the approach for fabricating NPs since its inception due to its efficiency and reproducibility. ${ }^{19,20}$ Nevertheless, these approaches are not free of drawbacks, such as the production of toxic by-products that can harm the environment and the use of harsh chemicals and extreme reaction conditions that sometimes require expensive equipment. ${ }^{21}$ The synthesis of these noble nanomaterials has been reported through a variety of physical and chemical methods. ${ }^{18,22,23}$ Wet chemical reduction is presented as one of the most useful synthetic approaches due to precise compositional, size and crystallographic control of the resulting nanomaterials. ${ }^{24}$ Nevertheless, the production of toxic by-products often happens with these methods, affecting the biocompatibility of the generated structures, with potentially dangerous effects from their interaction with biological tissue. ${ }^{25}$

Aiming to overcome the main limitations of the traditional synthesis of nanomaterials, green nanotechnology appears as a potential alternative. ${ }^{26}$ Green nanotechnology offers synthetic pathways that are both environmentally friendly and cost-effective approaches. These methods of synthesis include the use of biological organisms, such as bacteria, ${ }^{19,27}$ fungi ${ }^{28,29}$ or plants, ${ }^{30}$ and natural organic compounds, such as fruit extracts ${ }^{31}$ or polysaccharides, ${ }^{32}$ that have the ability to reduce metallic ions and stabilize the synthesized nanomaterials. Furthermore, hydrothermal methods have been gaining attention as green chemistry approaches due to the ability to adapt these reactions to environmentally friendly methods for NP production. ${ }^{33}$

From all of the aforementioned natural raw materials, biodegradable natural polymers, such as starch and chitosan, represent an outstanding alternative for the eco-friendly synthesis of noble metallic NPs. For instance, the starch-assisted synthesis of colloidal monometallic AgNPs and AuNPs has been extensively documented, ${ }^{34-39}$ but very few studies have reported the synthesis of colloidal starch-stabilized $\mathrm{Ag} / \mathrm{Au}$ alloy NPs. ${ }^{40-42}$ The chemical reducing properties of starch are related to the presence of glucose units that are formed when starch is hydrolyzed at high temperatures (around $95^{\circ} \mathrm{C}$ ) and at basic conditions. ${ }^{43}$ The glucose molecules are able to oxidize to carboxylic acids, and the metallic ions are reduced to a zero-valent metal. ${ }^{36}$ The capping properties of starch are given by its hydroxyl groups, which stabilize the metal NPs through inter- and intramolecular hydrogen bonding. ${ }^{34,35}$

Despite the relative simplicity, there have been few studies related to the use of starch-stabilized AgNPs or AuNPs in biomedical applications. Interestingly, the cytotoxic effect of starch-stabilized bimetallic Ag/AuNPs on any human cancer cell line has not been reported yet, while the anticancer effect of their monometallic counterparts has been well studied. For instance, AshaRani et $\mathrm{al}^{44}$ described the toxic effect of starch-coated AgNPs on human glioblastoma cells (U251). More recently, Borah et $\mathrm{al}^{38}$ reported the biosynthesis of $\mathrm{Au}$ 
nanoflowers (AuNFs) using an aqueous seed extract of Syzygium cumini (L.) as a bioreductant and starch as a capping agent and for its anticancer properties. In terms of antimicrobial activity against AMR bugs, just a few reports have been found in the literature concerning the use of noble NPs against antibiotic resistance strains: for instance, AgNPs have been used against methicillin-resistant Staphylococcus aureus (MRSA) ${ }^{45}$ as well as AuNPs. ${ }^{46}$ However, no reports have been found for the use of bimetallic Ag/AuNPs against these strains.

In the present work, we report a simple, environmentally friendly, cost-effective and highly reproducible green synthetic approach for the production of colloidal AuNPs and bimetallic $\mathrm{Ag} / \mathrm{AuNPs}$ using potato starch as the capping and reducing agent and water as the dispersion medium. NPs were characterized for their optical properties, colloid stability, particle size, morphology and composition using ultraviolet (UV)-visible spectroscopy, transmission electron microscopy (TEM), X-ray diffraction (XRD), dynamic light scattering (DLS), $\zeta$-potential, energy-dispersive X-ray spectroscopy (EDS) and inductively coupled plasma mass spectrometry (ICP-MS). Antimicrobial studies with commercially available antibiotic-resistant bacterial strains (MRSA and multidrug-resistant [MDR] Escherichia coli) as well as cytocompatibility and anticancer studies with human dermal fibroblast (HDF) and human melanoma cells, respectively, were completed in order to elucidate the biomedical applications of the novel green-synthesized noble metal NPs.

\section{Materials and methods Chemicals}

Silver nitrate $\left(\mathrm{AgNO}_{3}\right)$ was purchased from Thermo Fisher Scientific (Waltham, MA, USA), sodium tetrachloroaurate $\left(\mathrm{NaAuCl}_{4}\right)$ was purchased from Sigma-Aldrich Co. (St Louis, MO, USA) and sodium hydroxide $(\mathrm{NaOH})$ was purchased from Fermont (Monterrey, Mexico). All chemicals were used without further purification and were at a minimum 99\% purity. Starch powder was directly extracted from potatoes, and its chemical composition was determined by an enzymatic method revealing a $22.41 \pm 0.51 \mathrm{wt} \%$ amylose content. ${ }^{47}$ All experiments were completed using deionized water $(\sigma=18.2 \mathrm{M} \Omega \mathrm{cm})$. For cell fixation studies, poly-Llysine, cacodylate buffer, glutaraldehyde, liquid graphite and osmium tetroxide $\left(\mathrm{OsO}_{4}\right)$ were all purchased from EMS (Electron Microscopy Sciences, Hatfield, PA, USA).

\section{Synthesis of colloidal noble metal NPs}

The synthesis of colloidal AuNPs and Ag/Au alloy NPs (or simply Ag/AuNPs) was carried out using an improved method based on a previous work. ${ }^{47}$ Briefly, a $1 \% \mathrm{w} / \mathrm{v}$ starch
Table I Experimental parameters used in the synthesis of colloidal AuNPs and Ag/AuNPs

\begin{tabular}{|l|l|l|l|}
\hline System & $\begin{array}{l}\text { I\% (w/v) starch } \\
\text { solution }(\mu \mathrm{L})\end{array}$ & $\begin{array}{l}\mathbf{2 5} \mathbf{~ m M} \\
\mathbf{A g N O}_{3}(\mu \mathrm{L})\end{array}$ & $\begin{array}{l}25 \mathrm{mM} \\
\mathrm{NaAuCl}_{4}(\mu \mathrm{L})\end{array}$ \\
\hline $\mathrm{Ag} / \mathrm{AuNPs}$ & 500 & 250 & 250 \\
\hline AuNPs & 500 & 0 & 250 \\
\hline
\end{tabular}

Note: Reaction time was set to 2 hours at $70^{\circ} \mathrm{C}$ and $\mathrm{pH}=\mathrm{II}$ for both systems. Abbreviations: AgNPs, silver nanoparticles; AuNPs, gold nanoparticles.

solution was prepared using boiling water. The starch solution was heated under constant reflux and stirred for 30 minutes. Finally, the starch solution was centrifuged for 10 minutes at 3,500 rpm and the supernatant was used further. For the synthesis of noble metal NP colloids, the corresponding metal precursor solution was added at the end when the reaction mixture was at the preset temperature of $70^{\circ} \mathrm{C} \pm 1^{\circ} \mathrm{C}$ and $\mathrm{pH}=11 \pm 0.2$ (the $\mathrm{pH}$ value was determined using a $\mathrm{pH}$ Sensor from Vernier Software and Technology [Beaverton, OR, USA]). The reaction time was set to 2 hours, followed by a centrifugation process for 60 minutes at 12,500 rpm. For further characterization and application in antibacterial and cytotoxicity assays of the noble metal NPs, the supernatant was discarded and the pellet was redispersed in $10 \mathrm{~mL}$ of deionized water. Table 1 summarizes the experimental parameters used in the synthesis of the metal NP colloids.

\section{Characterization techniques}

UV-visible spectra were obtained using a PerkinElmer 365 spectrometer (PerkinElmer Inc., Waltham, MA, USA). Absorption spectra were measured in the range of 300 $800 \mathrm{~nm}$ with a speed scan of $20 \mathrm{~nm} / \mathrm{min}$ and a scan step of $0.5 \mathrm{~nm}$. The noble metal NP colloids were diluted at a 1:5 ratio with water to measure their absorption band.

Powder XRD patterns were recorded with a Rigaku MiniFlex 600 diffractometer operating with at a voltage of $40 \mathrm{kV}$, a current of $15 \mathrm{~mA}$ and with $\mathrm{Cu} \mathrm{K} \alpha$ radiation $(\lambda=1.542 \AA)$. All XRD patterns were obtained with a step width of $0.05^{\circ}(2 \theta)$ and scan speed of $0.2^{\circ} / \mathrm{min}$ at room temperature. The XRD samples were prepared by drying 6-8 $\mathrm{mL}$ of the metal colloids on the sample holder.

Fourier transform infrared (FT-IR) spectra were collected using a PerkinElmer Spectrum 400 FT-IR/FT-NIR (PerkinElmer, Waltham, MA, USA) in attenuated total reflectance (ATR) mode. For FT-IR spectroscopy measurements, $5 \mu \mathrm{g}$ of the solid noble metal NPs was used and the preparation of the sample was the same as for XRD analysis.

DLS measurements and the determination of $\zeta$-potential for particle size distribution and colloidal stability determination, respectively, were carried out using a Malvern Zetasizer 
Nano ZS (Malvern Instruments, Malvern, UK) in a 1:20 v/v dilution for AuNPs and Ag/AuNPs. Measurements were performed at $25.0^{\circ} \mathrm{C} \pm 0.1^{\circ} \mathrm{C}$ using disposable $\zeta$-potential cells. For both analysis, a He-Ne laser $(\lambda=633 \mathrm{~nm})$ and a backscattering detection configuration $\left(175^{\circ}\right)$ were used. The constants used for the sample measurements were 0.20 as the refractive index and 3.32 as the absorption value for both mono- and bimetallic NPs, respectively. For $\zeta$-potential analysis, the Smoluchowski approximation was used.

ICP-MS liquid sample analyses were carried out in a Thermo Scientific iCAP 6500 - ICP OES CID spectrometer (Thermo Scientific, Waltham, MA, USA), using a wavelength of $\lambda=328$ and $242.7 \mathrm{~nm}$ for $\mathrm{Ag}$ and $\mathrm{Au}$, respectively. Reference samples used were a $1,000 \mu \mathrm{L} / \mathrm{mL}$ Ag solution, a $1,000 \mu \mathrm{L} / \mathrm{mL}$ Au solution and a $100 \mu \mathrm{g} / \mathrm{mL}$ Au solution each in $2 \% \mathrm{HNO}_{3}$ from AccuStandard. Analytical quality control in the quantification of $\mathrm{Ag}$ and $\mathrm{Au}$ was asserted by multiple blanks and calibration curves using the reference samples, thus obtaining a correlation coefficient of 0.9998 and 0.9996 , respectively. The procedure detection limit was 0.12 and $2.0 \mu \mathrm{g} / \mathrm{mL}$ for $\mathrm{Ag}$ and $\mathrm{Au}$, respectively.

Scanning transmission electron microscopy (STEM) and high-resolution transmission electron microscopy (HRTEM) imaging were carried out using an FEI TITAN 80-300 (FEI Company, Hillsboro, OR, USA) equipped with a tungsten field emission gun operated at $300 \mathrm{kV}$. A calibrated EDS system (EDAX Inc., Mahwah, NJ, USA) integrated to the TEM provided for qualitative and quantitative elemental analysis. The TEM samples were prepared by drop casting the noble metal NP colloids on a carbon-coated copper grid followed by air drying. Prior to TEM imaging, the TEM samples were treated with oxygen plasma for 3 minutes to remove excess starch.

For cell fixation studies, a Cressington 208HR High Resolution Sputter Coater and a Samdri ${ }^{\circledR}$-PVT-3D Critical Point dryer were used to prepare the samples, which were imaged using a Hitachi S-4800 scanning electron microscopy (SEM) instrument at a $3 \mathrm{kV}$ accelerating voltage and $10 \mu \mathrm{A}$ of current.

\section{Bacterial culture}

Bacterial cultures of gram-negative (MDR E. coli; ATCC ${ }^{\circledR}$ BAA-2471; American Type Culture Collection [ATCC], Manassas, VA, USA) and gram-positive (MRSA; ATCC 4330; ATCC) bacteria were prepared for the experiments. The drug-resistant phenotypes were kept on agar plates at $4^{\circ} \mathrm{C}$ before proper use. For the preparation of the bacterial overnight cultures, $5 \mathrm{~mL}$ of sterile Luria-Bertani (LB; bioPLUS, bioWORLD) media was inoculated and subsequently incubated at $37^{\circ} \mathrm{C} / 200 \mathrm{rpm}$. After 24 hours, the optical density (OD) of the bacterial cultures was measured at $600 \mathrm{~nm}$ using a spectrophotometer (SpectraMax M3; Molecular Devices LLC, Sunnyvale, CA, USA). The bacterial suspensions were diluted at a concentration of $10^{6}$ colony-forming units per milliliter $(\mathrm{CFU} / \mathrm{mL})$ prior use.

\section{Antibacterial effects of noble metal NPs}

Twenty-four-hour growth-curve antibacterial assays were completed using metal NPs, bacteria and media. Different concentrations of NPs, from 1 to $20 \mu \mathrm{g} / \mathrm{mL}$, were prepared and mixed with the proper amount of media in a 96-well, clear flat-bottom plate (Thermo Fisher Scientific). A fixed volume of bacterial solution was then added to the wells. Untreated controls were prepared with media and bacterial solutions, without metal NPs. Controls containing NPs and medium alone were used to observe the innate absorbance of the NPs. The plate was introduced into a spectrophotometer, and samples were measured for 24 hours at $600 \mathrm{~nm}$ every 2 minutes.

The experimental bacterial growth curves were shifted to the origin and fitted with a modified Gompertz model. The statistical distribution was related to a mathematical formula (Equation 1) containing parameters that were translated into a biological meaning (Equation 2) after a series of derivations. ${ }^{48}$ Finally, the biological parameters were obtained as a function of the original mathematical parameters through a series of derivation and then substituting them into the original formula.

$$
\begin{gathered}
y(t)=a \exp [-\exp (b-c t)] \\
y(t)=A \exp \{-\exp [(e \mu) / A(\lambda-t)+1]\}
\end{gathered}
$$

In Equation 2, $y(t)$ is the dependent variable that represents the amount of bacteria growing as a function of time and $t$ is the time. The other parameters, $A, \mu$ and $\lambda$, represent the maximum value of bacterial growth (related to $y$ ), the maximal growth rate and the lag time, respectively. A least-squares estimation algorithm using a generalized reduced gradient (GRG) nonlinear solver was used to estimate the values of the three parameters.

With the aim to further quantify antibacterial properties, colony-counting unit assays were carried out using the same metal NP concentrations and the bacterial strains. A 96-well plate was prepared using the same protocol as for the previous assays. Immediately after, they were placed in a $37^{\circ} \mathrm{C}$ incubator for 8 hours. Following incubation, each one of the samples was diluted in sterile phosphate buffered 
saline (PBS; Sigma-Aldrich Co.) to obtain serial dilutions of $100 \times, 1,000 \times$ and $10,000 \times$. A $10 \mu \mathrm{L}$ aliquot was then taken from each one of the dilutions and placed onto a labeled agar plate, following a drop plate method. The plates were incubated for a proper time period (depending on each one of the bacterial strains) at $37^{\circ} \mathrm{C}$ inside an incubator. Following the second period of incubation, the colonies were counted using proper software.

\section{Analysis of NPs in bacteria by SEM}

Both bacterial strains (MDR E. coli and MRSA) were inoculated into $5 \mathrm{~mL}$ of sterile LB media in a $50 \mathrm{~mL}$ Falcon conical centrifuge tube and incubated at $37^{\circ} \mathrm{C} / 200 \mathrm{rpm}$ for 24 hours. The OD was then measured at $600 \mathrm{~nm}$ (OD600) using a spectrophotometer. The overnight suspension was diluted to a final bacterial concentration of $10^{6} \mathrm{CFU} / \mathrm{mL}$ prior to measuring the OD. A selected $10 \mu \mathrm{g} / \mathrm{mL} \mathrm{NP}$ concentration was mixed with LB media and bacterial solution in a sixwell plate with a glass coverslip attached to the bottom. The coverslips were pretreated with polylysine to enhance cell adhesion right before the experiment. The plate was placed inside an incubator for 8 hours at $37^{\circ} \mathrm{C}$. After the experiment, the coverslips were fixed with a primary fixative solution containing $2.5 \%$ glutaraldehyde and $0.1 \mathrm{M}$ sodium cacodylate buffer solution for 1 hour. Subsequently, the fixative solution was exchanged for $0.1 \mathrm{M}$ sodium cacodylate buffer and the coverslips were washed three times for 10 minutes. Post-fixation was done using a $1 \% \mathrm{OsO}_{4}$ solution in buffer for 1 hour. Subsequently, the coverslips were washed three times with buffer and dehydration was progressively achieved with $35 \%, 50 \%, 70 \%, 80 \%, 95 \%$ and $100 \%$ ethanol - three times for the $100 \%$ ethanol. Finally, the coverslips were dried by a liquid $\mathrm{CO}_{2}$-ethanol exchange in a Samdri-PVT-3D Critical Point dryer. The coverslips were mounted on SEM stubs with carbon adhesive tabs (EMS) after treatment with liquid graphite and then sputter coated with a thin layer of platinum using a Cressington 208HR High Resolution Sputter Coater. Digital images of the treated and untreated bacteria were acquired using an SEM.

\section{In vitro cytotoxicity assay with noble metal NPs}

Cytotoxicity assays were prepared using both healthy and cancerous human cell lines: HDF (ATCC ${ }^{\circledR}$ PCS-201-012; Manassas, VA) and melanoma (ATCC CRL-1619; ATCC) cells. The cells were grown separately in DMEM (Thermo Fisher Scientific), 10\% fetal bovine serum (FBS; ATCC 30-2020; ATCC) and 1\% penicillin/streptomycin (Thermo Fisher Scientific). To quantify the cytotoxicity of the NPs toward the cell lines, cell viability (3-(4,5-dimethylthiazol2-yl)-5-(3-carboxymethoxyphenyl)-2-(4-sulfophenyl)2H-tetrazolium [MTS]) assays (CellTiter $96{ }^{\circledR}$ AQueous One Solution Cell Proliferation Assay; Promega Corporation, Fitchburg, WI, USA) were carried out. The cells were seeded at a determined concentration of $5 \times 10^{4}$ cells $/ \mathrm{mL}$ in 96 -well plates and placed at $37^{\circ} \mathrm{C}$ in a humidified incubator with a 5\% carbon dioxide $\left(\mathrm{CO}_{2}\right)$ atmosphere for 24 hours; the media was then removed, and different concentrations of the NP colloids prepared in DMEM were added to each one of the wells. The plate was then incubated for 24 hours under the same environmental conditions. Following the second incubation period, the media was removed and MTS solution was added, leading to an incubation period of 4 hours before placing the plate in a spectrophotometer. The absorbance was then measured at $490 \mathrm{~nm}$, and the cell viability in response to various NP concentrations was determined.

\section{Statistical analyses}

All experiments were done in triplicate, and the experimental results were assessed for statistical significance using a Student's $t$-test ( $p \leq 0.05$ is considered significant).

\section{Results and discussion Synthesis of colloidal AuNPs and $\mathrm{Ag} / \mathrm{AuNPs}$}

The eco-friendly synthesis of colloidal AuNPs and Ag/AuNPs was carried out by a wet chemical reduction of the respective ions $\left(\mathrm{Ag}^{+}\right.$and $\left.\mathrm{AuCl}_{4}^{-}\right)$using water soluble starch as both the reducing and capping agent. Regarding the potential application of noble metal NPs in nanomedicine, it is fundamental to ensure the dispersibility of the NPs in water and hence in the culture media. For this purpose, the capping agent must be hydrophilic in nature and, more importantly, biocompatible; all these requirements are fulfilled by starch. ${ }^{44}$ During the synthesis of the noble metal NPs, the glucose molecules, released as the product of the hydrolysis of starch at high temperatures and basic conditions, ${ }^{43}$ were oxidized to gluconic acid (standard reduction potential $\left[E^{\circ}\right]$ at $\mathrm{pH} \approx 10$ of $-0.60 \mathrm{~V}$ versus the normal hydrogen electrode $[\mathrm{NHE}])^{49}$ and hence the precursor ions $\mathrm{Ag}^{+}\left(\mathrm{Ag}^{+} / \mathrm{Ag}^{\circ}, E^{\circ}=+0.80 \mathrm{~V}\right.$ versus $\left.\mathrm{NHE}\right)$ and $\mathrm{AuCl}_{4}^{-}\left(\mathrm{AuCl}_{4}^{-} / \mathrm{Au}^{\circ}, E^{\circ}=+1.00 \mathrm{~V}\right.$ versus NHE$)$ were reduced to their corresponding elemental forms. ${ }^{50}$ Regarding the coreduction of $\mathrm{Ag}^{+}$and $\mathrm{AuCl}_{4}^{-}$ions by glucose molecules, it is expected that $\mathrm{AgCl}$ will be formed as a by-product due to the galvanic replacement reaction between $\mathrm{Ag}(\mathrm{s})$ and $\mathrm{AuCl}_{4}^{-{ }^{-41}}$ Nevertheless, the precipitation of $\mathrm{AgCl}$ in the synthesis of $\mathrm{Ag} / \mathrm{Au}$ alloy NPs was not observed in the XRD analysis (vide infra). 


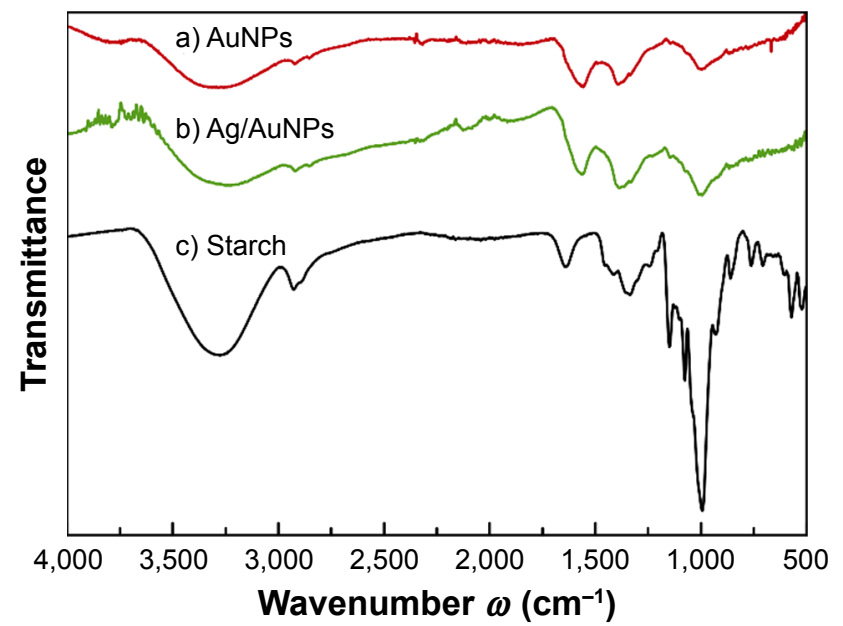

Figure I FT-IR spectra of samples (a) AuNPs, (b) Ag/AuNPs and (c) pure starch. Abbreviations: AgNPs, silver nanoparticles; AuNPs, gold nanoparticles; FT-IR, Fourier transform infrared.

\section{Determination of starch as a capping agent by FT-IR spectroscopy}

The FT-IR spectra of AuNPs, Ag/AuNPs and pure powder starch are compared as shown in Figure 1. All the samples showed a broad band at $3,403 \mathrm{~cm}^{-1}$ due to the stretching of hydroxyl groups and a band at $1,023 \mathrm{~cm}^{-1}$, which is characteristic of the $\mathrm{C}-\mathrm{O}$ stretching from the anhydroglucose rings. ${ }^{51}$ The band around $2,900 \mathrm{~cm}^{-1}$ was assigned to $\mathrm{C}-\mathrm{H}$ bond stretching related to the ring methylene hydrogen atoms. ${ }^{51}$ This confirmed the presence of starch as the stabilizing agent of the noble metal NPs. ${ }^{37}$

\section{Characterization of the optical properties of colloidal AuNPs and Ag/AuNPs by UV- visible spectroscopy}

During the reaction process, the initial colorless solutions turned to reddish and brownish transparent colloids, which indicated the synthesis of colloidal AuNPs and Ag/AuNPs, respectively, as can be seen in the inset of Figure 2. All the UV-visible absorption spectra of the noble metal colloids showed a single absorption band, in which the maximum wavelength $\left(\lambda_{\max }\right)$ related to the surface plasmon resonance (SPR) of quasi-spherical noble metal NPs was observed at $\lambda_{\text {max }}=463$ and $521 \mathrm{~nm}$ for Ag/AuNPs and AuNPs, respectively (Figure 2). This was in agreement with the values reported for $5-10 \mathrm{~nm} \mathrm{Ag} / \mathrm{Au}$ alloy NPs $\left(\lambda_{\max }=470 \mathrm{~nm}\right.$, for nominal atomic composition 1:1 $)^{52}$ and $27.4 \pm 2.0 \mathrm{~nm}$ AuNPs $\left(\lambda_{\max }=524 \pm 2 \mathrm{~nm}\right) .{ }^{53}$ The mean particle size $\left(D_{\text {mean }}\right)$ and standard deviation (SD) for the AuNPs in the dispersion were estimated using the empirical equation proposed by Khlebtsov, ${ }^{53}$ where $D=\left((X-17)^{1 / 2}-1\right) / 0.06$ in nm $\left(X=\lambda_{\max }-500\right)$ in nm for $X \geq 23 \mathrm{~nm}$. It is important to emphasize the fact that the

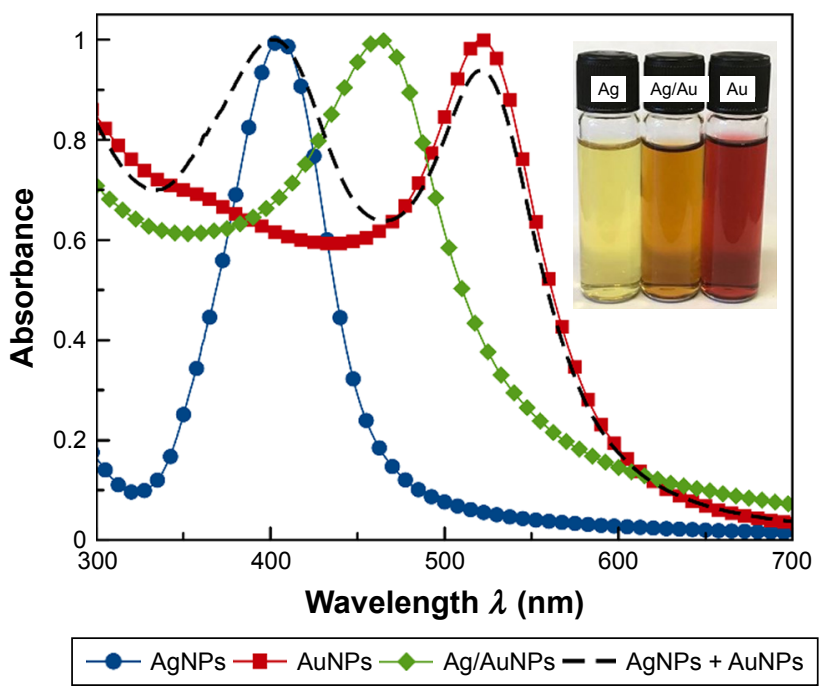

Figure 2 Comparison of the normalized UV-visible absorption spectra for colloidal AgNPs (blue/dot), Ag/AuNPs (green/square), AuNPs (red/diamond) and a physical mixture of colloidal AgNPs and AuNPs at a ratio I:I v/v. Inset: Photograph of the metallic NP colloids.

Abbreviations: AgNPs, silver nanoparticles; AuNPs, gold nanoparticles; NP, nanoparticle; UV, ultraviolet.

value for $D_{\text {mean }} \pm \mathrm{SD}$ calculated by $\mathrm{UV}$-visible spectroscopy was in excellent agreement with the values obtained by TEM imaging (28.5 $\pm 2.0 \mathrm{~nm}$ ) of the AuNPs; a comparison of particle size determination of the metallic NPs with other techniques is summarized in Table 2.

For the colloidal $\mathrm{Ag} / \mathrm{AuNPs}$ synthesized in this study, the $\lambda_{\text {max }}$ appeared at an intermediate value between AgNPs $\left(\lambda_{\max }=406 \pm 2 \mathrm{~nm}\right.$ [Figures 2 and S1]) and AuNPs, and its UV-visible absorption spectrum did not present additional bands or shoulders, as shown in Figure 2. This can be related to the characteristic SPR band for the alloy-type Ag/AuNPs. ${ }^{54}$ On the other hand, the UV-visible absorption spectrum of a physical mixture of pure colloidal AgNPs and pure colloidal AuNPs at a ratio $1: 1 \mathrm{v} / \mathrm{v}$ presented two bands at $\lambda_{\text {max }}=402$ and $521 \mathrm{~nm}$, which corresponded to the contribution of each of the noble metal NP colloids (Figure 2).

The reproducibility of our method for the synthesis of colloidal noble metal NPs was demonstrated by UV-visible

Table 2 Summary of particle size of the noble metal NP systems determined by DLS, TEM, UV-visible spectroscopy and XRD

\begin{tabular}{|l|l|l|l|l|}
\hline System & $\begin{array}{l}\mathbf{D L S}^{\mathbf{a}} \\
(\mathbf{n m})\end{array}$ & $\begin{array}{l}\text { TEM } \\
(\mathbf{n m})\end{array}$ & $\begin{array}{l}\text { UV-visible } \\
(\mathbf{n m})\end{array}$ & $\begin{array}{l}\mathbf{X R D}^{\mathrm{b}} \\
(\mathbf{n m})\end{array}$ \\
\hline Ag/AuNPs & $9.4 \pm 2.8$ & $9.7 \pm 3.2$ & $\sim 7$ & $10.3 \pm 4.5$ \\
\hline AuNPs & $29.3 \pm 8.6$ & $28.5 \pm 2.0$ & $27.4 \pm 2.0$ & $22.5 \pm 9.9$ \\
\hline
\end{tabular}

Notes: ${ }^{V}$ Values for DLS correspond to hydrodynamic diameter. ${ }^{b}$ alues for XRD correspond to crystallite size $(L)$.

Abbreviations: AgNPs, silver nanoparticles; AuNPs, gold nanoparticles; DLS, dynamic light scattering; NP, nanoparticle; TEM, transmission electron microscopy; UV, ultraviolet; XRD, X-ray diffraction. 

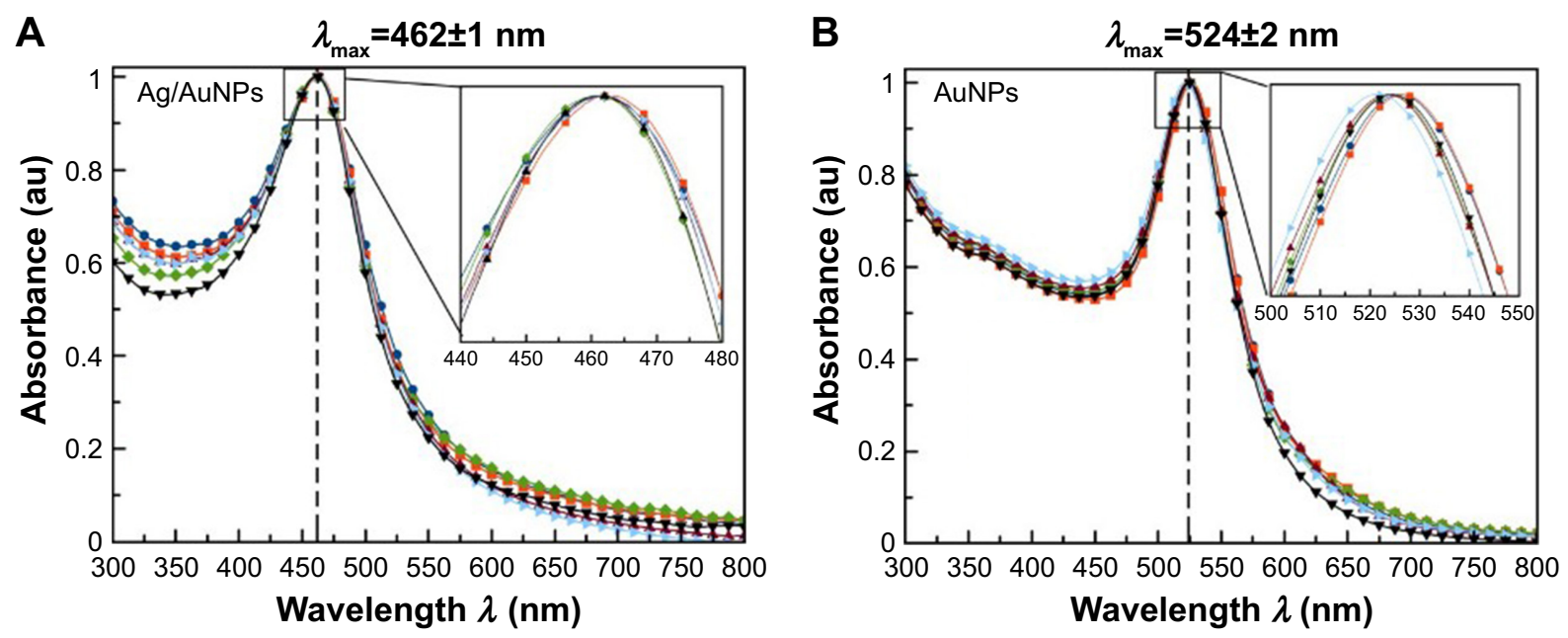

$\rightarrow$ Rep. $1 \rightarrow$ Rep. $2 \rightarrow$ Rep. $3 \rightarrow$ Rep. $4 \rightarrow$ Rep. $5 \rightarrow$ Rep. 6

Figure 3 Normalized UV-visible absorption spectra for colloidal (A) Ag/AuNPs and (B) AuNPs showing the average and SD for $\lambda_{\text {max }}$ of each colloidal system. Abbreviations: AgNPs, silver nanoparticles; AuNPs, gold nanoparticles; rep., repetition; UV, ultraviolet.

spectroscopy, which is an analytical technique that allows the estimation of concentration, degree of agglomeration and particle size of NPs stabilized in suspension. ${ }^{47,53,55}$ In Figure 3, we show the UV-visible absorption spectra for six sample batches that were independently synthesized for each colloidal metallic system. The maximum wavelength of the absorption bands $\left(\lambda_{\max }\right)$ was observed at $462 \pm 1$ and $524 \pm 2 \mathrm{~nm}$ for $\mathrm{Ag} / \mathrm{AuNPs}$ and AuNPs, respectively. The UV-visible absorption spectra did not show any significant changes between different batches, neither in the $\lambda_{\max }$ values nor in the shape and width of the bands, therefore demonstrating the high reproducibility of our methodology.

The stability of the colloidal noble metal NPs over time was also determined by UV-visible spectroscopy. As shown in Figure S2, the UV-visible spectra for each colloidal system measured up to 50 days for AuNPs and $\mathrm{Ag} / \mathrm{AuNPs}$ after their synthesis was shown. It can be observed that the noble metal colloids were relatively stable for both AuNPs and $\mathrm{Ag} / \mathrm{AuNPs}$, in which a slight red shift of the maximum wavelength of the absorption band $\left(\Delta \lambda_{\max }=+1\right.$ and $+3 \mathrm{~nm}$, for AuNPs and $\mathrm{Ag} / \mathrm{AuNPs}$, respectively) and a reduction in the absolute absorbance at the corresponding $\lambda_{\max }\left(\Delta \mathrm{Abs}^{\natural}\right.$ $\lambda_{\max }=-0.30$ and -0.02 , for AuNPs and Ag/AuNPs, respectively) were observed.

\section{Structural characterization of AuNPs and Ag/AuNPs by XRD analysis}

The XRD patterns for Ag/AuNPs and AuNPs are shown in Figure 4, along with the calculated XRD patterns for the bulk face-centered cubic (FCC) Ag and Au. The diffraction peaks observed at $2 \theta=38.3^{\circ}, 44.5^{\circ}, 64.8^{\circ}, 77.8^{\circ}$ and $81.8^{\circ}$ correspond to the (111), (200), (220), (311) and (222) crystallographic planes, respectively, for both bulk FCC Ag and $\mathrm{Au} .{ }^{56}$ The presence of foreign phases was not detected. The cubic lattice parameter $(a)$ was calculated for each crystallographic plane using Bragg's law $\left(\lambda=2 d_{\mathrm{hkl}} \cdot \sin \theta_{\mathrm{hkl}}\right)$, where $\lambda$ is the wavelength of the $\mathrm{X}$-ray radiation, $d_{\mathrm{hkl}}$ and $\theta_{\mathrm{hkl}}$ are the interplanar distance and diffraction angle, respectively, for a given crystallographic plane with Miller indices $(h k l)^{57}$ and the interplanar distance formula for a cubic unit cell $\left(a=d_{\mathrm{hkl}} \cdot\left[\mathrm{h}^{2}+\mathrm{k}^{2}+\mathrm{l}^{2}\right]\right)$. The lattice parameters $(a)$ found for the studied systems are in good agreement with previously reported values for AuNPs and 1:1 Ag/Au alloy NPs, ${ }^{52}$ as summarized in Table 3 . The mean crystallite size $(L)$ for each noble metal NP system was calculated using the Scherrer

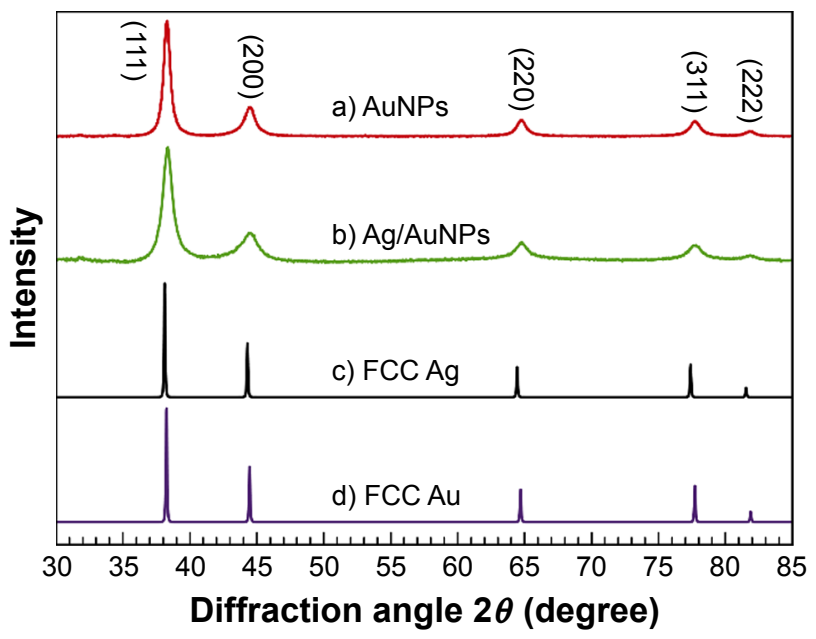

Figure 4 Comparison between the experimental XRD patterns for (a) AuNPs and (b) Ag/AuNPs and the calculated XRD patterns for bulk FCC (c) Ag and (d) Au. ${ }^{56}$ Abbreviations: AgNPs, silver nanoparticles; AuNPs, gold nanoparticles; FCC, facecentered cubic; XRD, X-ray diffraction. 
Table 3 Cubic lattice parameter (a) and crystallite size $(L)$ for $\mathrm{Ag} / \mathrm{AuNPs}$ and AuNPs, as calculated from experimental XRD patterns

\begin{tabular}{|l|l|l|l|}
\hline System & $\begin{array}{l}\text { Experimental } \\
(\boldsymbol{a} / \mathbf{A})\end{array}$ & $\begin{array}{l}\text { Reported values } \\
\text { for a/A }\end{array}$ & $\begin{array}{l}\text { Experimental } \\
(\mathbf{L} / \mathbf{n m})\end{array}$ \\
\hline $\mathrm{Ag} / \mathrm{AuNPs}$ & $4.065 \pm 0.008$ & 4.0562 & $10.3 \pm 4.5$ \\
\hline AuNPs & $4.075 \pm 0.002$ & 4.0762 & $23.5 \pm 10.3$ \\
\hline
\end{tabular}

Abbreviations: AgNPs, silver nanoparticles; AuNPs, gold nanoparticles; XRD, X-ray diffraction.

equation $\left(L=k \lambda /\left[B \cos \theta_{\mathrm{hk}}\right]\right)$, where $k$ is a dimensionless shape factor (0.94 assuming spherical crystallites) and $B$ is the full width at half maximum (FWHM) for a given diffraction peak. ${ }^{58}$ The results are summarized in Table 3.

\section{Hydrodynamic diameter determination and colloidal stability studies of the AuNPs and $\mathrm{Ag} / \mathrm{AuNPs}$ by DLS and $\zeta$-potential}

The hydrodynamic diameter of the noble metal NPs in suspension was determined experimentally by DLS, and the stability of the metal colloids was evaluated by $\zeta$-potential. Both measurements were carried out at $25^{\circ} \mathrm{C}$ and $37^{\circ} \mathrm{C}$ without any significant difference between their respective values. The results of DLS considered here were the number-based measurements obtained at $25^{\circ} \mathrm{C}$, which are shown in Figure $5 \mathrm{~A}$. The hydrodynamic diameter found by DLS was $29.3 \pm 8.6 \mathrm{~nm}$ and $9.4 \pm 2.8 \mathrm{~nm}$ for AuNPs and Ag/Au alloy NPs, respectively. These values are comparable to the crystallite size $(L)$ and particle size $(D)$ obtained through XRD analysis and TEM, respectively, as can be observed in Figure 5 and Table 2.

In general, a colloid or suspension is considered stable if the $\zeta$-potential is above a critical value of $\pm 30 \mathrm{mV} .{ }^{59,60}$ Taking into account that the $\zeta$-potential determination experiments were done within the first 2 days after the synthesis of the samples and given the measured $\zeta$-potential values for the colloidal AuNPs and Ag/AuNPs depicted in Figure 5B, our noble metal NP colloids can be considered stable.

\section{Particle size and morphology determination of AuNPs and Ag/AuNPs by TEM analysis}

The size and shape of the noble metal NPs were further characterized by TEM. For all of the noble metal nanosystems, the NPs were quasi-spherical and no evident agglomeration was observed (Figure 6). As shown in HRTEM images (insets of Figure 6), the samples consist of multiple twinned structure nanocrystals. This type of structure has been observed in mono-, bi- and trimetallic NP systems. ${ }^{52,61,62}$ The size distribution analysis (histogram) is shown in Figure 6, in which the values for the particle size are represented as the mean diameter $D_{\text {mean }} \pm \mathrm{SD}$ and the relative SD (RSD) in percentage was $28.5 \pm 2.0 \mathrm{~nm}(7.0 \%)$ and $9.7 \pm 3.2 \mathrm{~nm}$ (32.1\%) for AuNPs and Ag/AuNPs, respectively. The values for $D_{\text {mean }}$ determined by TEM analysis for both noble NP systems are in good agreement with the hydrodynamic diameter, particle size and crystallite size as determined by DLS, UV-visible spectroscopy and XRD analysis, respectively. A comparison of the results is summarized in Table 2.

\section{Chemical composition determination of AuNPs and Ag/AuNPs by EDS and ICP-MS analysis}

The chemical composition of individual alloyed bimetallic NPs was analyzed by EDS. As shown in Figure S3, the EDS spectra of single Ag/AuNPs (nominal Ag:Au atomic

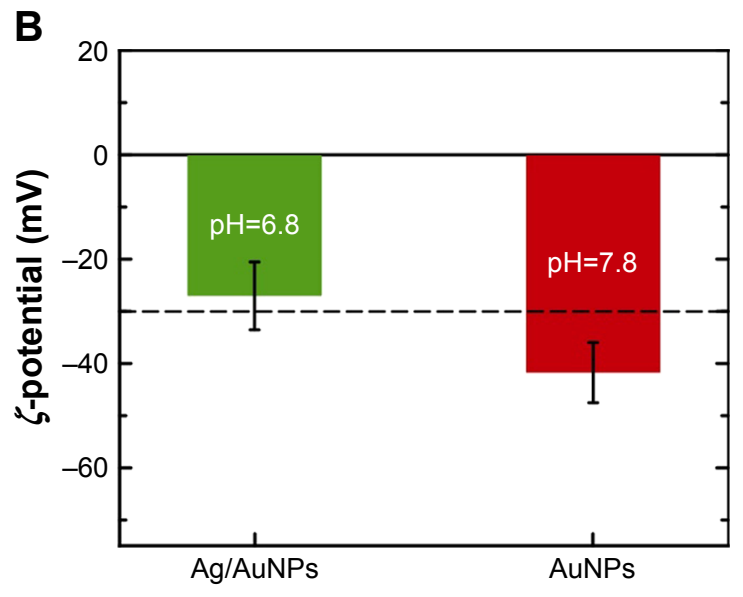

Figure 5 (A) Hydrodynamic diameter distribution obtained by DLS and (B) $\zeta$-potential values. Both measurements were carried out at $25^{\circ} \mathrm{C}$. Abbreviations: AgNPs, silver nanoparticles; AuNPs, gold nanoparticles; DLS, dynamic light scattering. 
A

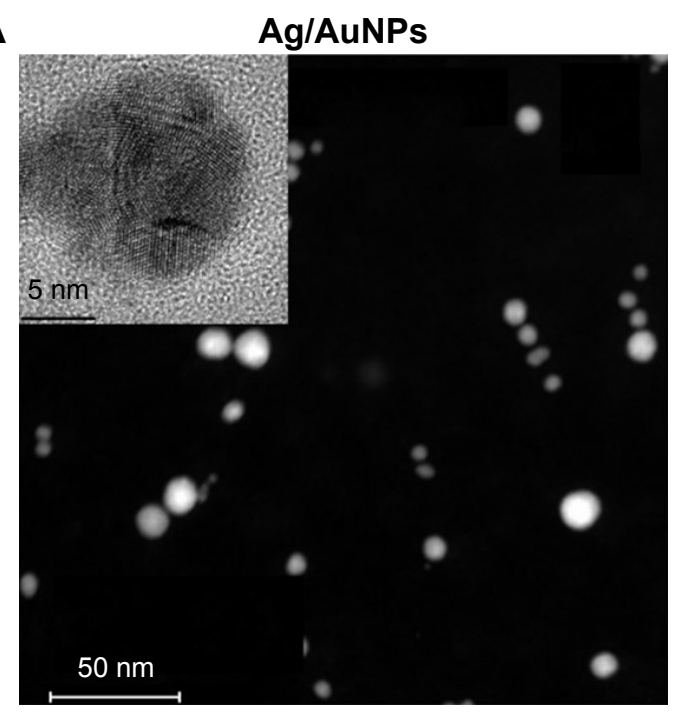

B AuNPs

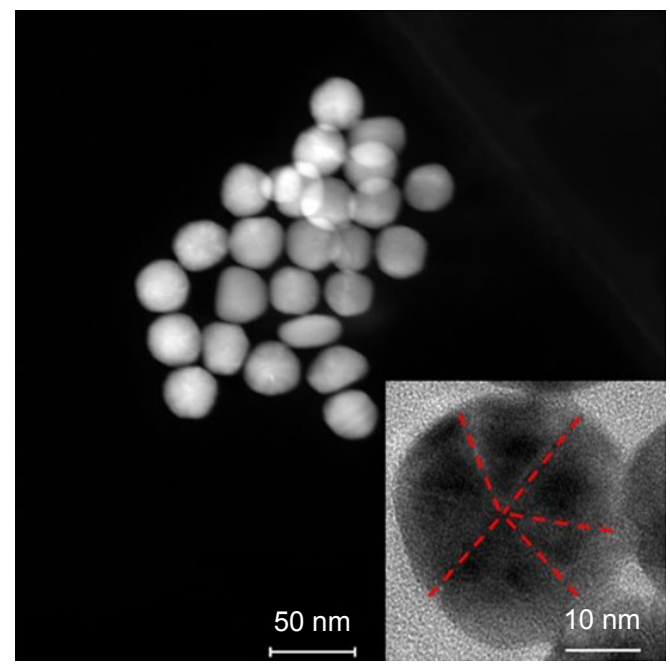

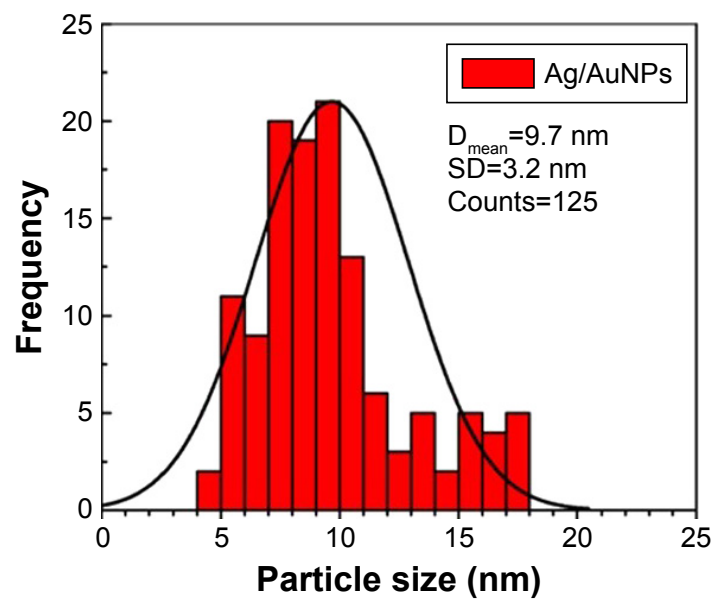

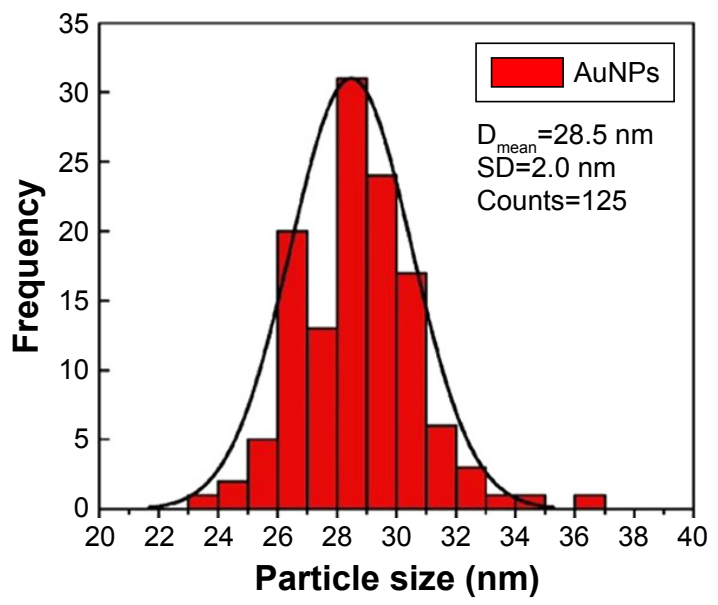

Figure 6 STEM images and particle size distribution for (A) Ag/AuNPs and (B) AuNPs. Insets: HRTEM images. The red lines in the HRTEM image in (B) show the twin planes in the Au nanocrystals.

Abbreviations: AgNPs, silver nanoparticles; AuNPs, gold nanoparticles; $D_{\text {mean }}$, mean particle size; HRTEM, high-resolution transmission electron microscopy; STEM, scanning transmission electron microscopy.

ratio $=1.00$ ) revealed a composition of $44.97 \pm 3.87 \mathrm{at} \% \mathrm{Ag}$ and 55.03 $\pm 3.87 \mathrm{at} \% \mathrm{Au}, \mathrm{ie}, \mathrm{Ag}: \mathrm{Au}$ atomic ratio $=0.818$.

The chemical content of the colloidal AuNPs and $\mathrm{Ag} / \mathrm{AuNPs}$ was determined by ICP-MS analysis. The molar concentrations were found to be $95.8 \mu \mathrm{g} / \mathrm{mL}$ for colloidal AuNPs. With respect to the $\mathrm{Ag} / \mathrm{Au}$ alloy NP colloid, the results confirmed the presence of both noble metals with concentrations of 17.0 and $35.1 \mu \mathrm{g} / \mathrm{mL}$ for $\mathrm{Ag}$ and $\mathrm{Au}$, respectively, ie, $\mathrm{Ag}: \mathrm{Au}$ atomic ratio $=1.13$, which is close to the composition of the feed ion molar concentration ratio $\left(\mathrm{Ag}^{+}: \mathrm{AuCl}_{4}^{-}=1.00\right)$.

\section{Antimicrobial properties of AuNPs and Ag/AuNPs}

To determine the antibacterial activity of the AuNPs and Ag/AuNPs, antibacterial assays were completed using two bacterial strains that show antibiotic resistance: MRSA and MDR E. coli. NP concentrations used for all of the experiments were between 1 and $20 \mu \mathrm{g} / \mathrm{mL}$ for the AuNPs and Ag/AuNPs.

When MDR E. coli was cultured in the presence of the noble metal NPs, the bacterial growth was delayed. For AuNPs, the degree of this delay increased with a rise in NP concentration, especially noticeable for concentrations between 10 and $20 \mu \mathrm{g} / \mathrm{mL}$ for MDR E. coli (Figure 7A) and MRSA (Figure 7B); while for the bimetallic Ag/AuNPs, this delay was enhanced with respect to the monometallic counterpart, specially noticeable at the highest concentration $(20 \mu \mathrm{g} / \mathrm{mL})$ in experiments with MDR E. coli (Figure 7C) and at concentrations higher than $10 \mu \mathrm{g} / \mathrm{mL}$ for MRSA (Figure 7D).

Using suitable software, the parameters of the modified Gompertz equation (Equation 2) were obtained and 


\section{A}
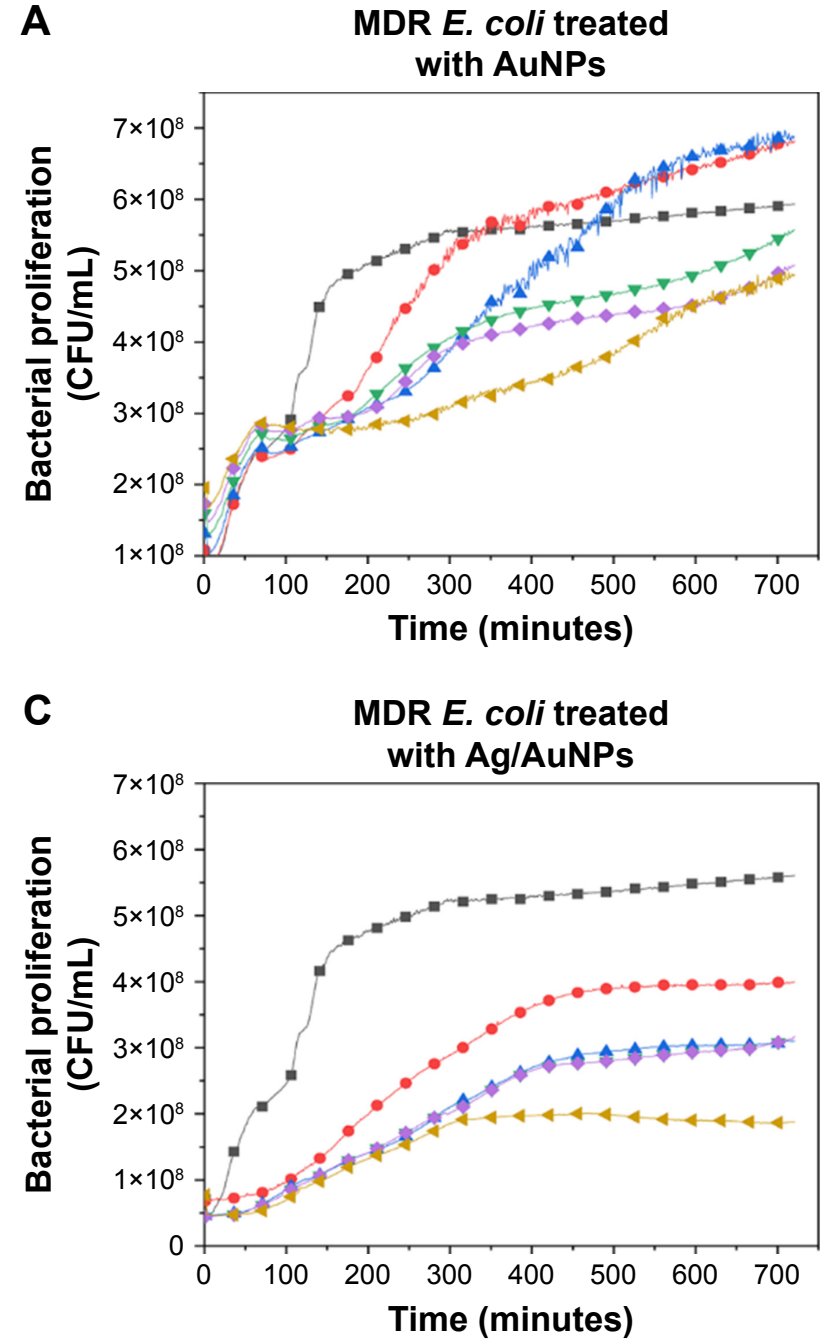

B

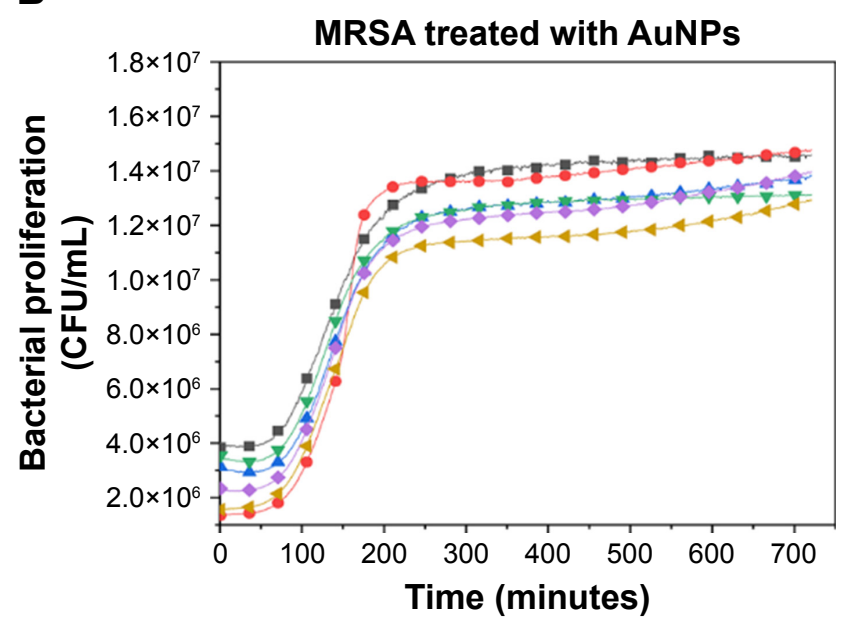

D

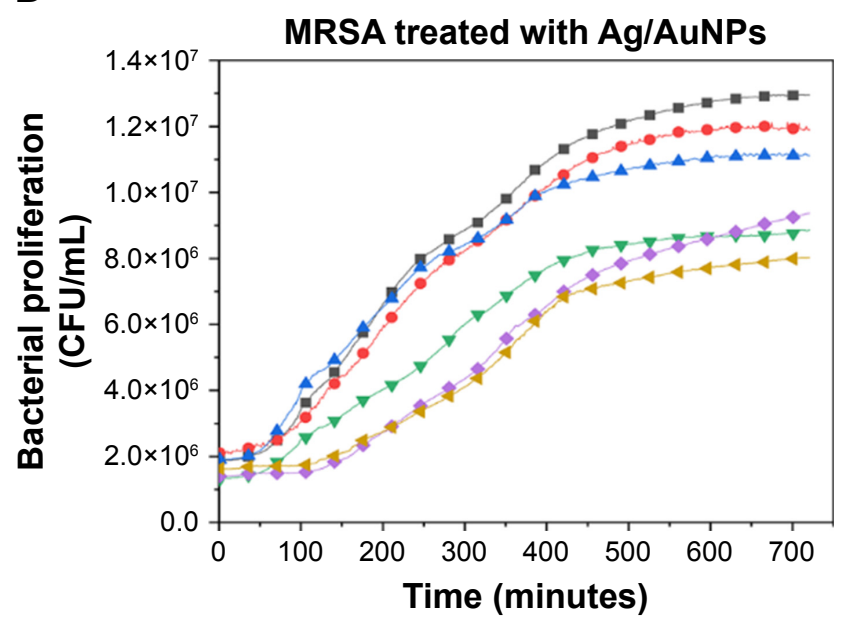

$-0 \mu \mathrm{g} / \mathrm{mL} \rightarrow 1 \mu \mathrm{g} / \mathrm{mL} \quad \longleftarrow 5 \mu \mathrm{g} / \mathrm{mL} \quad \rightarrow 10 \mu \mathrm{g} / \mathrm{mL} \quad \leftarrow 15 \mu \mathrm{g} / \mathrm{mL} \quad \longleftarrow 20 \mu \mathrm{g} / \mathrm{mL}$

Figure 7 AuNPs (A, B) and Ag/AuNPs (C, D) decrease the growth of MDR E. coli and MRSA. Growth of a $10^{6} \mathrm{CFU} / \mathrm{mL}$ suspension of both bacterial strains over 24 hours in the presence of different concentrations of mono- and bimetallic NPs. The values represent the mean $\pm S D$, data $=$ mean \pm SD, $N=3$.

Abbreviations: AgNPs, silver nanoparticles; AuNPs, gold nanoparticles; CFU, colony-forming unit; MDR E. coli, multidrug-resistant Escherichia coli; MRSA, methicillinresistant Staphylococcus aureus; NP, nanoparticle.

subsequently plotted for statistical analysis (Figure 8). The maximum bacterial growth achieved by each one of the bacterial strains was quantified by measuring parameter $A$ (Figure 8A and B). A significant antibacterial effect was present in the case of bimetallic Ag/AuNPs for both experiments. Additionally, larger concentrations of NPs caused a decrease in value of parameter $A$, meaning a smaller maximum bacterial growth for MDR E. coli (Figure 8A). In general, this delay shows that there was a clear antimicrobial activity for the bimetallic $\mathrm{Ag} / \mathrm{AuNPs}$ compared to an irregular trend for the monometallic AuNPs.

Changes in maximum bacterial growth rate were determined by analyzing the parameter $\mu$ (Figure $8 \mathrm{C}$ and $\mathrm{D}$ ).
These analyses demonstrated that higher NP concentrations resulted in a lower growth rate for the bacteria. This trend was similar for both bacterial experiments. However, the behavior became significant for the bimetallic Ag/AuNPs in the treatment of MRSA compared to their monometallic counterparts.

To quantify the potential changes in the lag phase in the bacterial growth, parameter $\lambda$ was plotted (Figure $8 \mathrm{E}$ and $\mathrm{F}$ ). This analysis showed that higher NP concentrations led to a larger lag phase in bacterial growth. This was especially visible when AuNPs were present in MDR E. coli cultures (Figure 8E), while there was a similar behavior with no significant changes for experiments with MRSA (Figure 8F). 
A
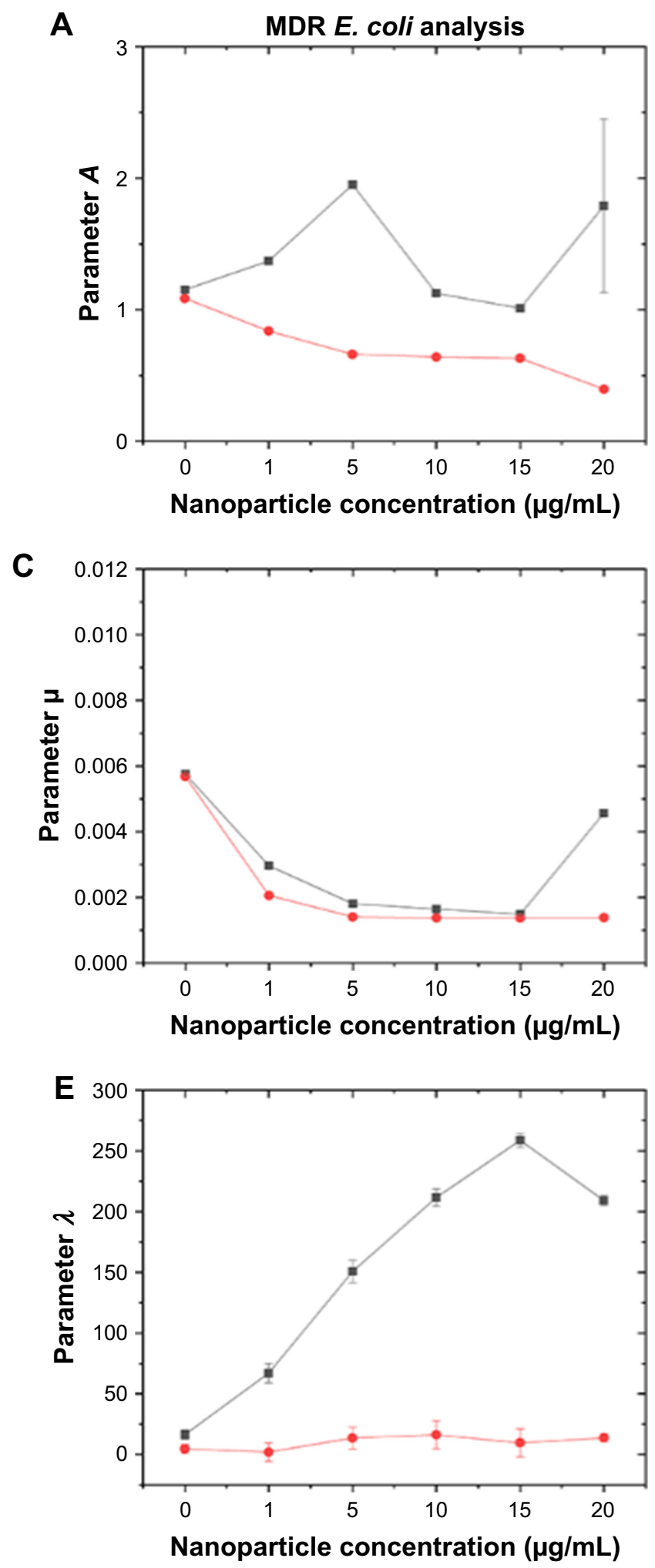

B
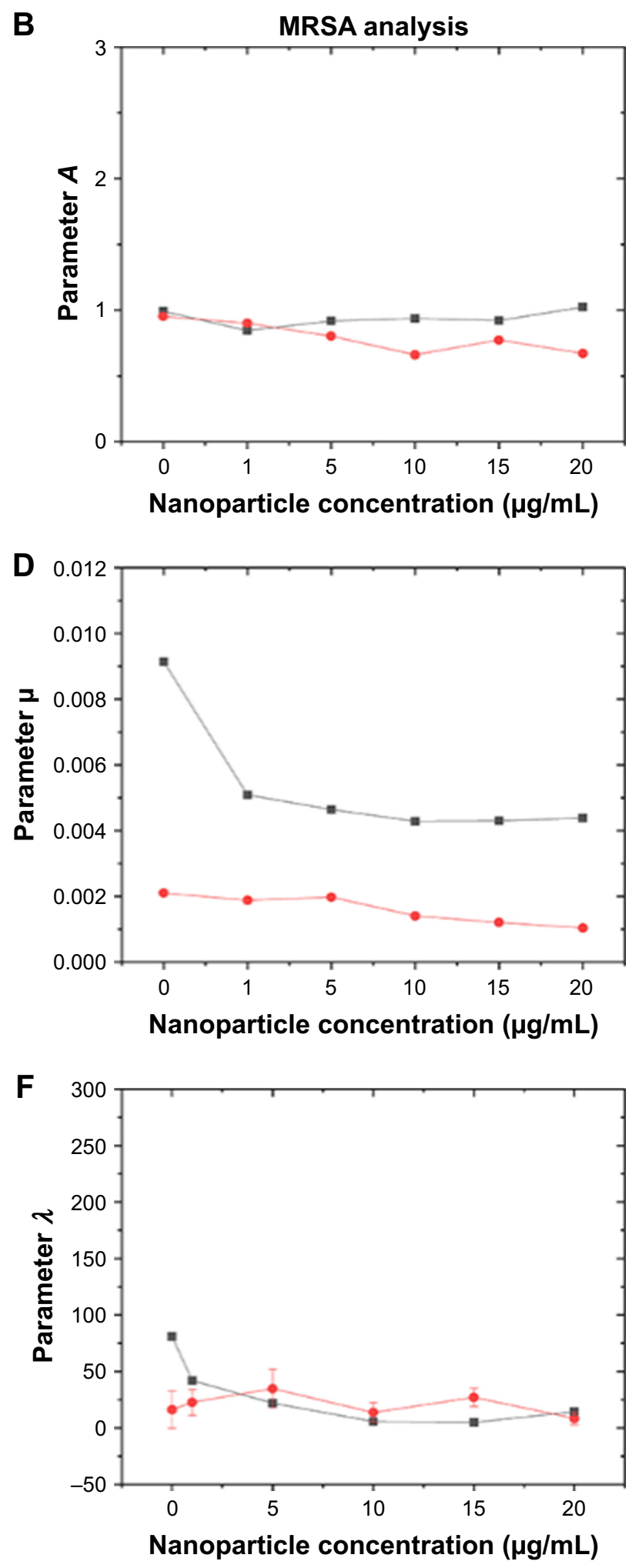

AuNPs

$\because A g / A u N P s$

Figure 8 Modified Gompertz equation parameters A (A, B), $\mu(\mathbf{C}, \mathbf{D})$ and $\lambda(\mathbf{E}, \mathbf{F})$ for increasing concentrations of NPs. Growth of a $10^{6} \mathrm{CFU} / \mathrm{mL}$ suspension of MDR E. coli and MRSA over 24 hours in the presence of different concentrations of NPs. The values represent the mean \pm SD, data $=$ mean \pm SD, N=3.

Abbreviations: AgNPs, silver nanoparticles; AuNPs, gold nanoparticles; CFU, colony-forming unit; MDR E. coli, multidrug-resistant Escherichia coli; MRSA, methicillinresistant Staphylococcus aureus; NP, nanoparticle. 
Inhibition of bacterial growth was therefore obtained due to the presence of the metal NPs.

Additional quantification of the bacterial growth inhibition was assessed using colony-counting unit assays. For experiments with MDR E. coli (Figure 9A), an antibacterial effect was observed at concentrations of AuNPs ranging between 10 and $20 \mu \mathrm{g} / \mathrm{mL}$, with no significant inhibition at lower concentrations; while MRSA treatment with the same NPs (Figure 9B) showed no significant antibacterial effect over the whole range of NP concentrations, with a slight delay in the bacterial growth at the highest concentration. On the other hand, when the bimetallic Ag/AuNPs were tested towards MDR E. coli (Figure 9C), an antibacterial effect was observed at NP concentrations ranging between 1 and $20 \mu \mathrm{g} / \mathrm{mL}$, with significant inhibition (larger than 50\% inhibition of total bacterial growth) at low concentrations. When the same NPs were tested with MRSA (Figure 9D), a noticeable antimicrobial effect was found at concentrations between 10 and $20 \mu \mathrm{g} / \mathrm{mL}$ in comparison with monometallic AuNPs.

The results confirmed the antibacterial effect of the NPs, with a trend especially noticeable in the case of bimetallic $\mathrm{Ag} / \mathrm{AuNPs}$ that develop enhanced antimicrobial activity in comparison to monometallic AuNPs. A clear trend of inhibition was found when MDR E. coli was cultured with the nanomaterials, with the larger NP concentrations causing increased inhibition. Although the inhibition in the case of
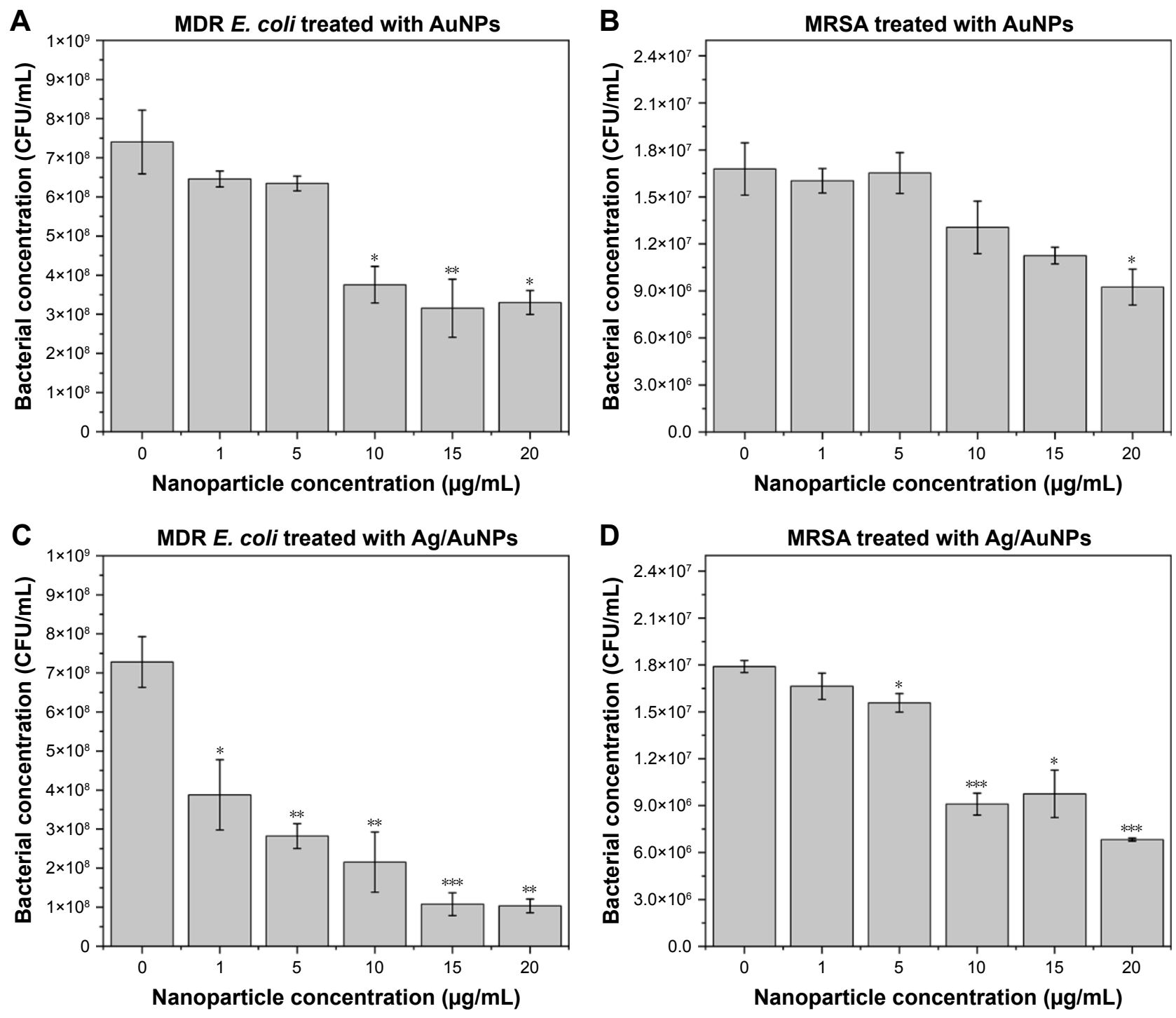

Figure 9 Colony-counting assay of MDR E. coli (A, C) and MRSA (B, D) after being treated for 8 hours with monometallic AuNPs and bimetallic Ag/AuNPs. Data $=$ mean \pm SD, $\mathrm{N}=3$. ${ }^{*} p<0.1$ versus control $\left(0 \mu \mathrm{g} / \mathrm{mL}\right.$ concentration), ${ }^{* *} p<0.05$ versus control $(0 \mu \mathrm{g} / \mathrm{mL}$ concentration $)$ and $* * * p<0.0005$ versus control $(0 \mu \mathrm{g} / \mathrm{mL}$ concentration). Statistical analysis performed was based on a t-distribution.

Abbreviations: AgNPs, silver nanoparticles; AuNPs, gold nanoparticles; CFU, colony-forming unit; MDR E. coli, multidrug-resistant Escherichia coli; MRSA, methicillinresistant Staphylococcus aureus. 
Table $4 I_{50}$ values for different noble metal NPs against MDR E. coli and MRSA

\begin{tabular}{|l|l|l|}
\hline System & $\begin{array}{l}\text { MDR E. coli IC } \text { I0 }_{50} I \\
(\mu \mathrm{g} / \mathrm{mL})\end{array}$ & $\begin{array}{l}\text { MRSA IC }_{50} I \\
(\mu \mathrm{g} / \mathrm{mL})\end{array}$ \\
\hline AuNPs & $7.02 \pm 1.31$ & $12.29 \pm 3.77$ \\
\hline Ag/AuNPs & $4.92 \pm 0.81$ & $6.95 \pm 1.70$ \\
\hline
\end{tabular}

Note: Error values are given for each one of the parameters.

Abbreviations: AgNPs, silver nanoparticles; AuNPs, gold nanoparticles; MDR E. coli, multidrug-resistant Escherichia coli; MRSA, methicillin-resistant Staphylococcus aureus; NP, nanoparticle.

MRSA reached more than $50 \%$ at some concentrations of $\mathrm{Ag} / \mathrm{AuNPs}$, there was not a significant difference in inhibition between mono- and bimetallic NPs. $\mathrm{IC}_{50}$ values were obtained with the aim to show the minimum inhibitory concentration for each one of the bacterial tests (Table 4). These values were much lower than the ones reported for colloidal AuNPs against bacteria. ${ }^{63,64}$ Therefore, the NP systems reported in this study showed an enhancement in the antimicrobial properties compared to other reported nanomaterials.

The observed antibacterial activity for both monometallic AuNPs and bimetallic Ag/AuNPs may be explained by the increased production of reactive oxygen species (ROS) within the biological tissue once the NPs reach the bacterial membrane ${ }^{65}$ Another factor that might be related to the antimicrobial activity is the size of the NPs. ${ }^{8}$ Since the present nanomaterials are relatively small, the penetration within the bacterial membrane is favored. However, further studies should be completed in order to corroborate these assumptions.

\section{SEM cell fixation study}

The morphological changes of AuNP- and Ag/AuNP-treated bacteria were extensively studied by SEM after NP exposure (Figure 10). Bacterial cells from both MDR E. coli and MRSA controls without NP treatment showed smooth and undamaged cells (Figure S4).

In the particular case of MDR E. coli experiments, untreated cells prepared for SEM micrographs were longer and displayed a smooth and intact surface. However, when the cells were exposed to both NPs (Figure 10A and B), the surface looked corrugated, with the presence of some dimples, as well as they displayed a shorter average length, indicating that the bacteria were not able to grow to maximum length. Besides, the presence of numerous flagella in control cells was lacking after treatment, indicating damage in the cell wall. After treatment, almost all of the cells showed rumples.

Untreated MRSA bacterial cells showed cells that were undamaged, while after incubation with NPs (Figure 10C and $\mathrm{D}$ ), the vast majority showed decreased diameters and
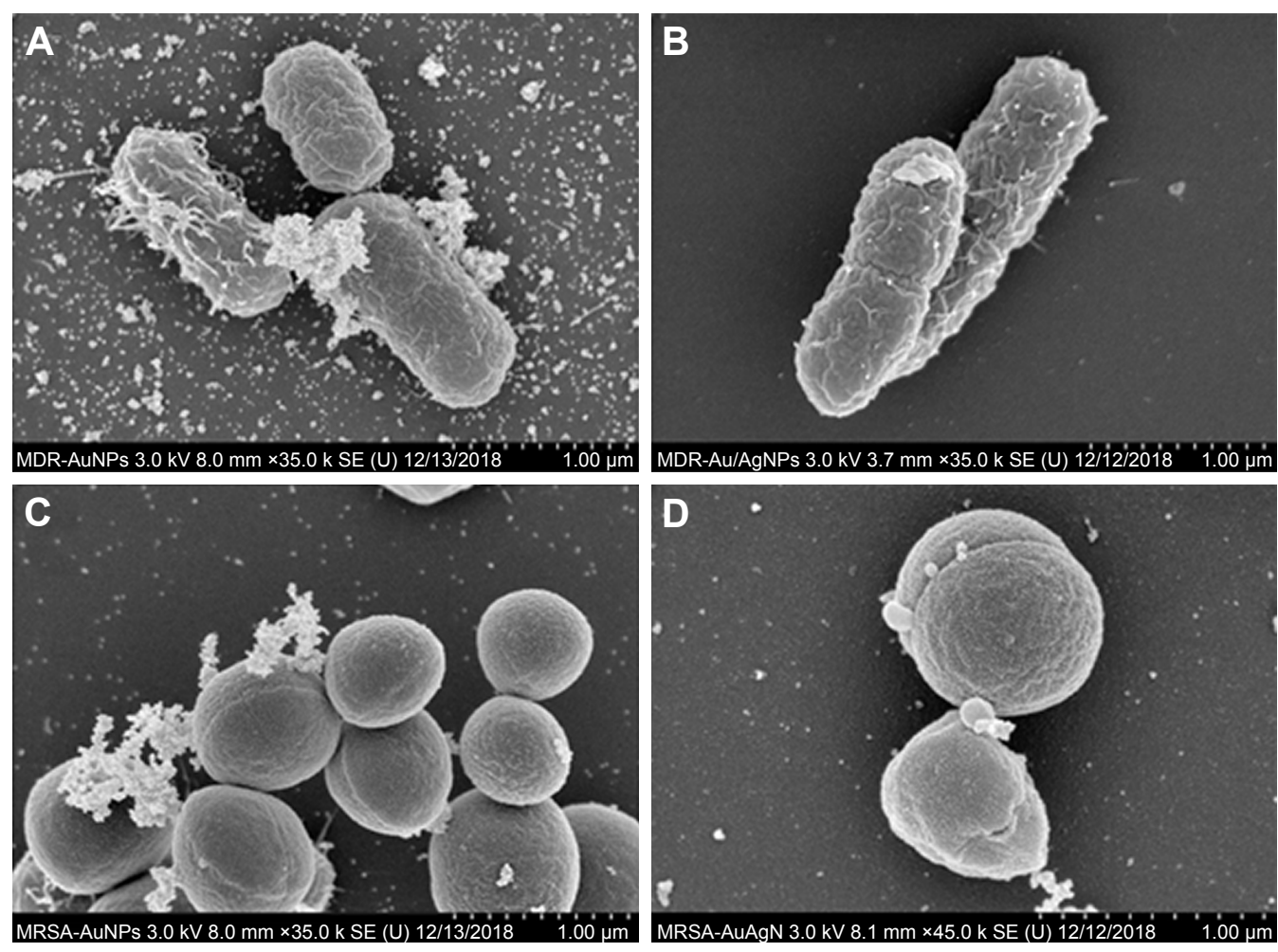

Figure 10 SEM micrographs of MDR E. coli and MRSA cells after 8 hours of treatment with AuNPs (A, C) and Ag/AuNPs (B, D), respectively.

Abbreviations: AgNPs, silver nanoparticles; AuNPs, gold nanoparticles; MDR E. coli, multidrug-resistant Escherichia coli; MRSA, methicillin-resistant Staphylococcus aureus; SEM, scanning electron microscopy. 

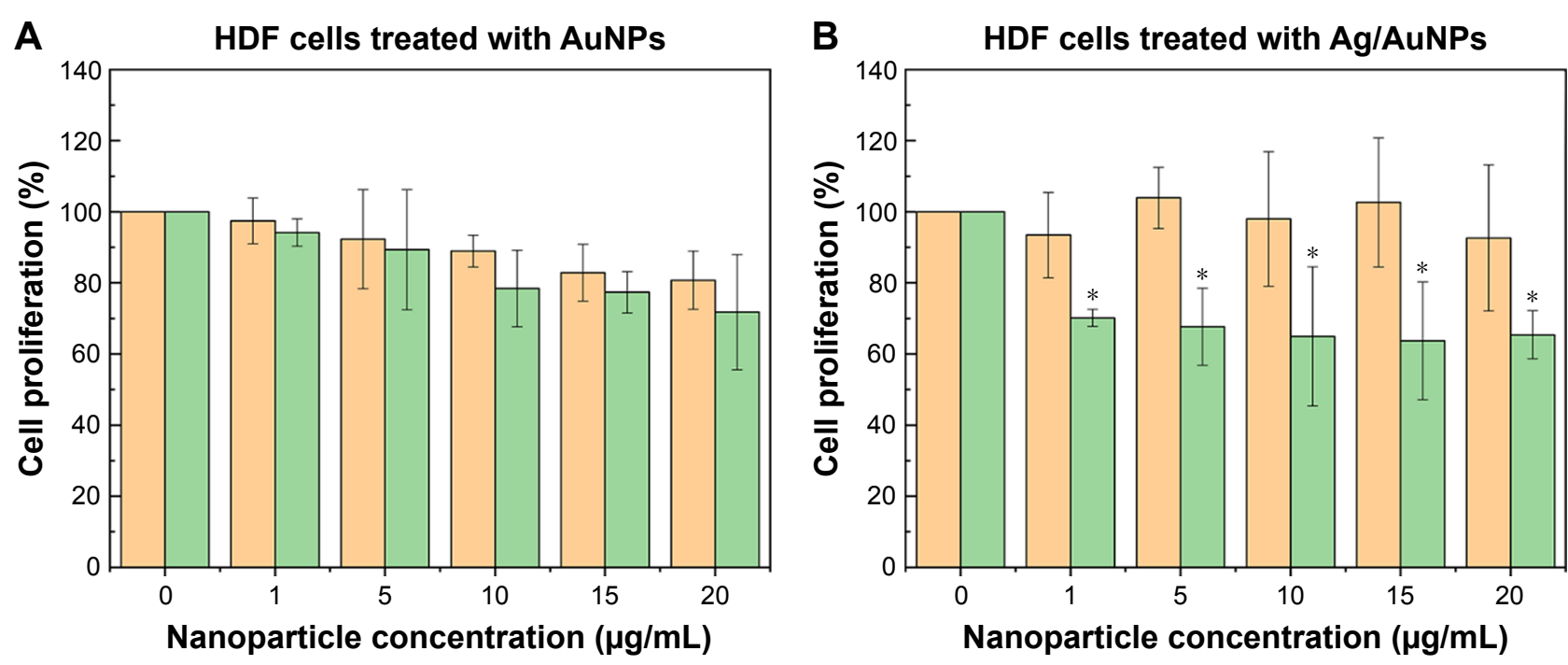

$\square 24$ hours $\square 72$ hours

Figure I I MTS assay on HDF cells in the presence of AuNPs $(\mathbf{A})$ and $\mathrm{Ag} / \mathrm{AuNPs}(\mathbf{B})$ at concentrations ranging from I to $20 \mu \mathrm{g} / \mathrm{mL}$. Data $=\mathrm{mean} \pm \mathrm{SD}, \mathrm{N}=3 . * \mathrm{p}<0.0 \mathrm{I}$ versus control $(0 \mu \mathrm{g} / \mathrm{mL}$ concentration), Statistical analysis performed was based on a t-distribution.

Abbreviations: AgNPs, silver nanoparticles; AuNPs, gold nanoparticles; HDF, human dermal fibroblast.

different stages of damage in the cell membrane, with some cells having dents and some cells appearing lysed.

In vitro cytotoxicity of AuNPs and $\mathrm{Ag} / \mathrm{AuNPs}$ in HDF and human melanoma cells

Cytotoxicity of both monometallic AuNPs and bimetallic $\mathrm{Ag} / \mathrm{AuNPs}$ was confirmed toward HDF and melanoma cells. The experiments were performed with NP concentrations ranging between 1 and $20 \mu \mathrm{g} / \mathrm{mL}$ for time periods between 1 and 3 days.

For AuNPs, at NP concentrations between 1 and $20 \mu \mathrm{g} / \mathrm{mL}$, no significant cytotoxicity in HDF (Figure 11A) was found. Besides, a slight delay in the cell proliferation was found on the third day of the experiment compared to the control. A higher cytotoxic effect was found over the same range of concentrations when Ag/AuNPs (Figure 11B) were tested with the cells, especially significant on the third
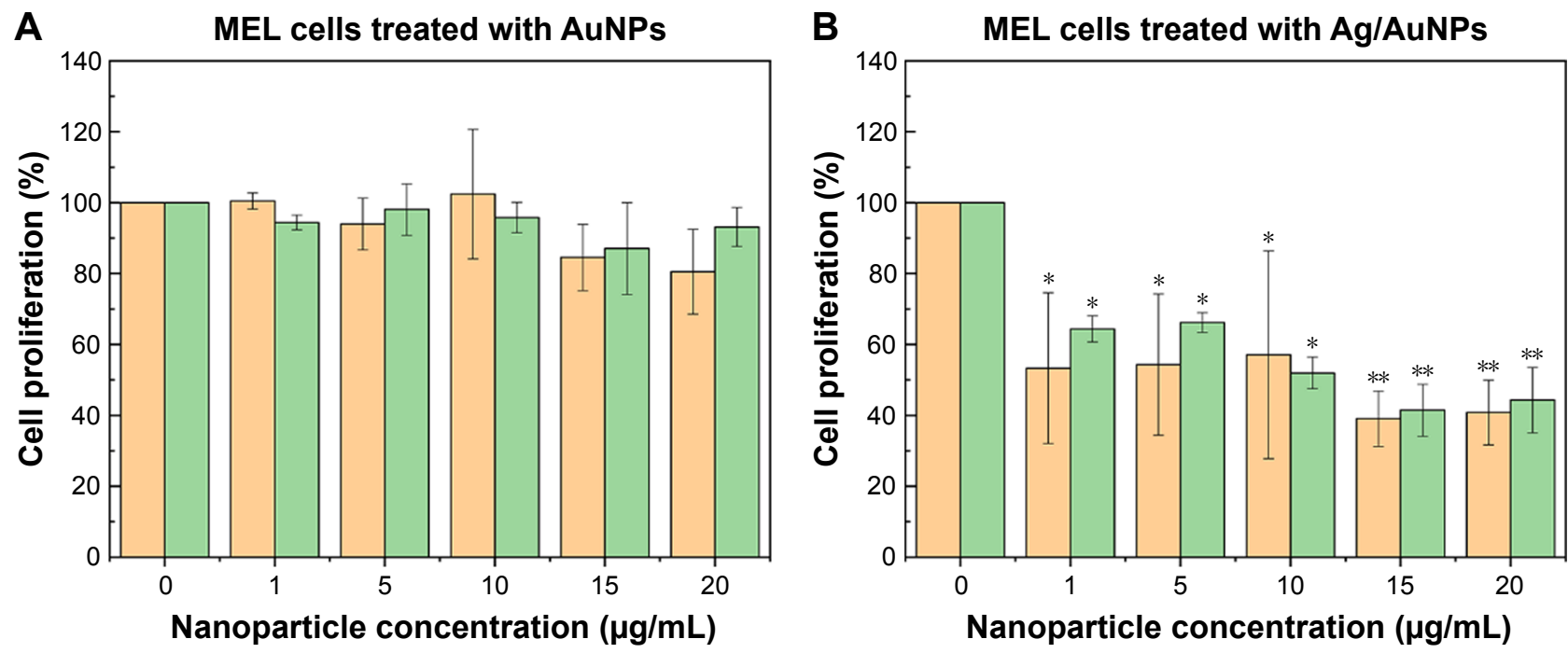

24 hours $\square 72$ hours

Figure 12 MTS assay on melanoma cells in the presence of AuNPs $(\mathbf{A})$ and $A g / A u N P s(B)$ at concentrations ranging from I to $20 \mu g / m L$. Data $=$ mean \pm SD, $N=3$. ${ }^{*} p<0.0$ I versus control $\left(0 \mu \mathrm{g} / \mathrm{mL}\right.$ concentration), ${ }^{* *} p<0.005$ versus control $(0 \mu \mathrm{g} / \mathrm{mL}$ concentration). Statistical analysis performed was based on a t-distribution. Abbreviations: AgNPs, silver nanoparticles; AuNPs, gold nanoparticles. 
day of the experiment. However, over $60 \%$ of the cells grew and proliferated. Therefore, there was no significant cytotoxic effect for both NPs.

When human melanoma cells were cultured with AuNPs (Figure 12A), no significant cytotoxic effect was found, with no noticeable inhibition of cell proliferation over the complete concentration range for both days of measurements. However, bimetallic Ag/AuNPs showed a high degree of inhibition of cell proliferation, with a significant depletion at 15 and $20 \mu \mathrm{g} / \mathrm{mL}$ (Figure 12B). After 72 hours, melanoma cells grew under the same trend of inhibition, with a larger NP concentration causing a greater depletion on cell proliferation.

Therefore, here, starch-stabilized AuNPs were cytocompatible over the complete range of concentrations, showing no significant inhibition of the cell proliferation for cancer cells, while their bimetallic starch-stabilized Ag/AuNP counterparts showed a similar cytocompatibility trend, but with anticancer activity, with cell proliferation inhibition close to $50 \%$ for most of the studied NP concentration range.

\section{Conclusion}

We present here a highly reproducible green synthesis method and thorough characterization of colloidal monometallic AuNPs and bimetallic Ag/Au alloy NPs using starch as the reducing and capping agent. The synthesized noble metal NPs were quasi-spherical in shape and presented the typical FCC crystal structure for $\mathrm{Au}$ and $\mathrm{Ag} / \mathrm{Au}$ alloy. Although the synthesized AuNPs were highly monodispersed with particle sizes of $28.5 \pm 2.0 \mathrm{~nm}$, the Ag/AuNPs showed a higher polydispersity degree with particle sizes of $9.7 \pm 3.2 \mathrm{~nm}$.

The antimicrobial activity of the starch-stabilized noble metal colloids demonstrated promising results as antibacterial agents toward MDR E. coli and MRSA. In particular, the $\mathrm{Ag} / \mathrm{AuNPs}$ showed an enhanced antimicrobial activity against MRSA in comparison to the monometallic Au nanosystem. Moreover, the anticancer therapeutic potential of the mono- and bimetallic NPs was tested on human melanoma cells showing a differentiated cytotoxic activity in the range of $10-20 \mu \mathrm{g} / \mathrm{mL}$, whereas no significant cytotoxicity in HDF cells was present at the same range of NP concentrations.

Further research is needed to determine the anticancer and antibacterial mechanism of the noble metal NPs synthesized in the present study in order to optimize their physicochemical characteristics and improve their selectivity.

\section{Acknowledgments}

JLCD thanks the School of Engineering and Sciences at Tecnologico de Monterrey through the Research Group on
Photonics and Quantum Systems for financial support. DLM, AVC, JC and TJW thank the Department of Chemical Engineering at Northeastern University for funding. The authors thank Elda Gómez for FT-IR spectroscopy measurements and Juan José Cortés-Morales from Centro del Agua para América Latina y el Caribe at Tecnologico de Monterrey for the determination of colloidal NP chemical composition by ICP-MS.

\section{Disclosure}

The authors report no conflicts of interest in this work.

\section{References}

1. Fleming A. On the antibacterial action of cultures of a penicillium, with special reference to their use in the isolation of B. influenzae. Br J Exp Pathol. 1929;10(3):226-236. doi:10.1093/clinids/2.1.129

2. Ventola CL. The antibiotic resistance crisis: part 1: causes and threats. Pharmacol Ther. 2015;40(4):277-283.

3. Zaman SB, Hussain MA, Nye R, Mehta V, Mamun KT, Hossain N. A review on antibiotic resistance: alarm bells are ringing. Cureus. 2017; 9(6):e1403. doi:10.7759/cureus.1403

4. Davies J, Davies D. Origins and evolution of antibiotic resistance. Microbiol Mol Biol Rev. 2010;74(3):417-433. doi:10.1128/MMBR. 00016-10

5. Llor C, Bjerrum L. Antimicrobial resistance: risk associated with antibiotic overuse and initiatives to reduce the problem. Ther Adv Drug Saf. 2014;5(6):229-241. doi:10.1177/2042098614554919

6. Li B, Webster TJ. Bacteria antibiotic resistance: new challenges and opportunities for implant-associated orthopaedic infections J Orthop Res. 2018;36(1):22-32. doi:10.1002/jor.23656.Bacteria

7. Shamaila S, Zafar N, Riaz S, Sharif R, Nazir J, Naseem S. Gold nanoparticles: an efficient antimicrobial agent against enteric bacterial human pathogen. Nanomaterials. 2016;6(4):71. doi:10.3390/nano6040071

8. Wang L, Hu C, Shao L. The antimicrobial activity of nanoparticles: present situation and prospects for the future. Int J Nanomedicine. 2017; 12:1227-1249. doi:10.2147/IJN.S121956

9. Niemirowicz K, Prokop I, Wilczewska AZ, et al. Magnetic nanoparticles enhance the anticancer activity of cathelicidin LL-37 peptide against colon cancer cells. Int J Nanomedicine. 2015;10:3843-3853. doi:10.2147/IJN.S76104

10. Wu M, Huang S. Magnetic nanoparticles in cancer diagnosis, drug delivery and treatment (Review). Mol Clin Oncol. 2017;7:738-746. doi:10.3892/mco.2017.1399

11. Rigo C, Ferroni L, Tocco I, et al. Active silver nanoparticles for wound healing. Int J Mol Sci. 2013;14(3):4817-4840. doi:10.3390/ ijms 14034817

12. Wang Y-F, Liu L, Xue X, Liang X-J. Nanoparticle-based drug delivery systems: what can they really do in vivo? F1000Research. 2017;6:681. doi:10.12688/f1000research.9690.1

13. Yamada M, Foote M, Prow TW. Therapeutic gold, silver, and platinum nanoparticles. WIREs Nanomed Nanobiotechnol. 2015;7(3):428-445. doi:10.1002/wnan.1322

14. Kim JS, Kuk E, Yu KN, et al. Antimicrobial effects of silver nanoparticles. Nanomedicine. 2007;3(1):95-101. doi:10.1016/j.nano.2006.12.001

15. Buttacavoli M, Albanese NN, Di Cara G, et al. Anticancer activity of biogenerated silver nanoparticles: an integrated proteomic investigation. Oncotarget. 2018;9(11):9685-9705. doi:10.18632/oncotarget .23859

16. Alkilany AM, Murphy CJ. Toxicity and cellular uptake of gold nanoparticles: what we have learned so far? J Nanopart Res. 2010; 12(7):2313-2333. doi:10.1007/s11051-010-9911-8

17. Sperling RA, Gil PR, Zhang F, Zanella M, Parak WJ. Biological applications of gold nanoparticles. Chem Soc Rev. 2008;37(9):1896-1908. doi:10.1039/b712170a 
18. Mallin MP, Murphy CJ. Solution-phase synthesis of sub-10 nm Au-Ag alloy nanoparticles. Nano Lett. 2002;2(11):1235-1237. doi:10.1021/ n1025774n

19. Iravani S, Korbekandi H, Mirmohammadi SV, Zolfaghari B. Synthesis of silver nanoparticles: chemical, physical and biological methods. Res Pharm Sci. 2014;9(6):385-406.

20. Ali A, Zafar H, Zia M, et al. Synthesis, characterization, applications, and challenges of iron oxide nanoparticles. Nanotechnol Sci Appl. 2016; 9:49-67. doi:10.2147/NSA.S99986

21. Ray PC, Yu H, Fu PP. Toxicity and environmental risks of nanomaterials: challenges and future needs. J Environ Sci Health C Environ Carcinog Ecotoxicol Rev. 2009;27(1):1-35. Toxicity. doi:10.1080/ 10590500802708267

22. Schmidt AA, Anton R. Anomalous growth-behavior of Pd-Au and Ag-Au alloy particles during vapor-deposition on carbon substrates at elevatedtemperatures. Surf Sci. 1995;322(1-3):307-324.

23. Senapati S, Ahmad A, Khan MI, Sastry M, Kumar R. Extracellular biosynthesis of bimetallic Au-Ag alloy nanoparticles. Small. 2005;1(5): 517-520. doi:10.1002/smll.200400053

24. Tao AR, Habas S, Yang P. Shape control of colloidal metal nanocrystals. Small. 2008;4(3):310-325. doi:10.1002/smll.200701295

25. Nadagouda MN, Hoag G, Collins J, Varma RS. Green synthesis of $\mathrm{Au}$ nanostructures at room temperature using biodegradable plant surfactants. Cryst Growth Des. 2009;9(11):4979-4983. doi:10.1021/ $\operatorname{cg} 9007685$

26. Makarov VV, Love AJ, Sinitsyna OV, et al. Green synthesis of metal nanoparticles using plants. Acta Naturae. 2014;6(1):35-44. doi:10.1039/ c1gc15386b

27. Medina Cruz D, Mi G, Webster TJ. Synthesis and characterization of biogenic selenium nanoparticles with antimicrobial properties made by Staphylococcus aureus, methicillin-resistant Staphylococcus aureus (MRSA), Escherichia coli, and Pseudomonas aeruginosa. J Biomed Mater Res A. 2018;106A(5):1400-1412. doi:10.1002/ jbm.a.36347

28. Costa Silva LP, Pinto Oliveira J, Keijok WJ, et al. Extracellular biosynthesis of silver nanoparticles using the cell-free filtrate of nematophagous fungus Duddingtonia flagrans. Int J Nanomedicine. 2017;12: 6373-6381. doi:10.2147/IJN.S137703

29. Ghareib M, Tahon MA, Saif MM, Abdallah WE-S. Rapid extracellular biosynthesis of silver nanoparticles by cunninghamella phaeospora culture supernatant. Iran J Pharm Res. 2016;15(4):915-924.

30. Kuppusamy P, Yusoff MM, Maniam GP, Govindan N. Biosynthesis of metallic nanoparticles using plant derivatives and their new avenues in pharmacological applications - an updated report. Saudi Pharm J. 2016;24(4):473-484. doi:10.1016/j.jsps.2014.11.013

31. Saif S, Tahir A, Chen Y. Green synthesis of iron nanoparticles and their environmental applications and implications. Nanomaterials. 2016; 6(11):209. doi:10.3390/nano6110209

32. Iconaru SL, Prodan AM, Motelica-Heino M, Sizaret S, Predoi D. Synthesis and characterization of polysaccharide-maghemite composite nanoparticles and their antibacterial properties. Nanoscale Res Lett. 2012;7:576. doi:10.1016/j.colsurfa.2010.10.015

33. Brown CD, Medina Cruz D, Roy AK, Webster TJ. Synthesis and characterization of PVP-coated tellurium nanorods and their antibacterial and anticancer properties. J Nanopart Res. 2018;20:254. doi:10.1007/ s11051-018-4354-8

34. Raveendran P, Fu J, Wallen SL. Completely "green" synthesis and stabilization of metal nanoparticles. J Am Chem Soc. 2003;125(46): 13940-13941. doi:10.1021/ja029267j

35. Vigneshwaran N, Nachane RP, Balasubramanya RH, Varadarajan PV. A novel one-pot "green" synthesis of stable silver nanoparticles using soluble starch. Carbohydr Res. 2006;341(12):2012-2018. doi:10.1016/j. carres.2006.04.042

36. Ayala Valencia G, de Oliveira Vercik LC, Ferrari R, Vercik A. Synthesis and characterization of silver nanoparticles using water-soluble starch and its antibacterial activity on Staphylococcus aureus. Starch - Stärke. 2013;65(11-12):931-937. doi:10.1002/star.201200252
37. Ban DK, Pratihar SK, Paul S. Controlled modification of starch in the synthesis of gold nanoparticles with tunable optical properties and their application in heavy metal sensing. $R S C A d v$. 2015;5(99):81554-81564. doi:10.1039/c5ra16473g

38. Borah D, Hazarika M, Tailor P, et al. Starch-templated biosynthesis of gold nanoflowers for in vitro antimicrobial and anticancer activities. Appl Nanosci. 2018;8(3):241-253. doi:10.1007/ s13204-018-0793-x

39. Engelbrekt C, Sørensen KH, Zhang J, Welinder AC, Jensen PS, Ulstrup J. Green synthesis of gold nanoparticles with starch-glucose and application in bioelectrochemistry. J Mater Chem. 2009;19(42): 7839-7847. doi:10.1039/b911111e

40. Raveendran P, Fu J, Wallen SL. A simple and "green" method for the synthesis of $\mathrm{Au}, \mathrm{Ag}$, and $\mathrm{Au}-\mathrm{Ag}$ alloy nanoparticles. Green Chem. 2006;8(1):34-38. doi:10.1039/B512540E

41. Xia B, He F, Li L. Preparation of bimetallic nanoparticles using a facile green synthesis method and their application. Langmuir. 2013; 29(15):4901-4907. doi:10.1021/la400355u

42. Malathi S, Ezhilarasu T, Abiraman T, Balasubramanian S. One pot green synthesis of $\mathrm{Ag}, \mathrm{Au}$ and $\mathrm{Au}-\mathrm{Ag}$ alloy nanoparticles using isonicotinic acid hydrazide and starch. Carbohydr Polym. 2014;111:734-743. doi:10.1016/j.carbpol.2014.04.105

43. Ortega-Arroyo L, Martin-Martinez ES, Aguilar-Mendez MA, CruzOrea A, Hernandez-Pérez I, Glorieux C. Green synthesis method of silver nanoparticles using starch as capping agent applied the methodology of surface response. Starch - Stärke. 2013;65(9-10):814-821. doi:10.1002/star.201200255

44. AshaRani PV, Low Kah Mun G, Hande MP, Valiyaveettil S. Cytotoxicity and genotoxicity of silver nanoparticles in human cells. ACS Nano. 2009;3(2):279-290. doi:10.1021/nn800596w

45. Akram FE, El-Tayeb T, Abou-Aisha K, El-Azizi M. A combination of silver nanoparticles and visible blue light enhances the antibacterial efficacy of ineffective antibiotics against methicillin-resistant Staphylococcus aureus (MRSA). Ann Clin Microbiol Antimicrob. 2016;15:48. doi:10.1186/s12941-016-0164-y

46. Mocan L, Matea C, Tabaran FA, et al. Selective in vitro photothermal nano-therapy of MRSA infections mediated by IgG conjugated gold nanoparticles. Sci Rep. 2016;6:39466. doi:10.1038/srep39466

47. Cholula-Díaz JL, Lomelí-Marroquín D, Pramanick B, Nieto-Argüello A, Cantú-Castillo LA, Hwang H. Synthesis of colloidal silver nanoparticle clusters and their application in ascorbic acid detection by SERS. Colloids Surf B Biointerfaces. 2018;163:329-335. doi:10.1016/j. colsurfb.2017.12.051

48. Tjørve KMC, Tjørve E. The use of Gompertz models in growth analyses, and new Gompertz-model approach: an addition to the UnifiedRichards family. PLoS One. 2017;12(6):e0178691. doi:10.1371/journal. pone. 0178691

49. Wingard LB, Liu CC, Kagda NL. Electrochemical measurements with glucose oxidase immobilized in polyacrylamide gel: constant current voltametry. Biotechnol Bioeng. 1971;13:629-639. doi:10.1002/ bit.260130504

50. Vanýsek P. Electrochemical series. In: Lide DR, editor. CRC Handbook of Chemistry and Physics. Boca Raton: CRC Press; 2005:5-80-5-89.

51. Fang JM, Fowler PA, Tomkinson J, Hill CAS. The preparation and characterisation of a series of chemically modified potato starches. Carbohydr Polym. 2002;47(3):245-252. doi:10.1016/S0144-8617(01) 00187-4

52. Ristig S, Prymak O, Loza K, et al. Nanostructure of wet-chemically prepared, polymer-stabilized silver-gold nanoalloys $(6 \mathrm{~nm})$ over the entire composition range. J Mater Chem B. 2015;3(23):4654-4662. doi:10.1039/C5TB00644A

53. Khlebtsov NG. Determination of size and concentration of gold nanoparticles from UV-Vis spectra. Anal Chem. 2008;80:6620-6625. doi:10.1021/ac0702084

54. Csapó E, Oszkó A, Varga E, et al. Synthesis and characterization of Ag/ $\mathrm{Au}$ alloy and core( $\mathrm{Ag})$-shell(Au) nanoparticles. Colloids Surf A Physicochem Eng Asp. 2012;415:281-287. doi:10.1016/j.colsurfa.2012.09.005 
55. Amendola V, Meneghetti M. Size evaluation of gold nanoparticles by UV-vis spectroscopy. J Phys Chem C. 2009;113:4277-4285. doi:10. 1021/jp8082425

56. Suh I-K, Ohta H, Waseda Y. High-temperature thermal expansion of six metallic elements measured by dilatation method and X-ray diffraction. J Mater Sci. 1988;23(2):757-760. doi:10.1007/BF01174717

57. Bragg WH, Bragg WL. The reflection of X-rays by crystals. Proc $R$ Soc A. 1913;88(605):428-438. doi:10.1098/rspa.1913.0040

58. Scherrer P. Bestimmung der Größe und der inneren Struktur von Kolloidteilchen mittels Röntgenstrahlen. Nachrichten von der Gesellschaft der Wissenschaften zu Göttingen, Math Klasse. 1918;1918: 98-100.

59. Capek I. Noble Metal Nanoparticles: Preparation, Composite Nanostructures, Biodecoration and Collective Properties. 1st ed. Tokyo: Springer Japan; 2017.

60. Liu J, Liang C, Zhu X, Lin Y, Zhang H, Wu S. Understanding the solvent molecules induced spontaneous growth of uncapped tellurium nanoparticles. Sci Rep. 2016;6:32631. doi:10.1038/srep32631

61. Elechiguerra JL, Reyes-Gasga J, Yacaman MJ. The role of twinning in shape evolution of anisotropic noble metal. J Mater Chem. 2006;16: 3906-3919. doi:10.1039/B607128G
62. Khanal S, Bhattarai N, McMaster D, Bahena D, Velazquez-Salazar JJ, Jose-Yacaman MJ. Highly monodisperse multiple twinned $\mathrm{AuCu}-\mathrm{Pt}$ trimetallic nanoparticles with high index surfaces. Phys Chem Chem Phys. 2014;16(30):16278-16283. doi:10.1039/ c4cp02208d.Highly

63. Kumar R, Shukla SK, Pandey M, Pandey A, Pathak A, Dikshit A. Synthesis and antimicrobial effects of colloidal gold nanoparticles against prevalent waterborne bacterial pathogens. Cogent Chem. 2016; 2:1192522. doi:10.1080/23312009.2016.1192522

64. Francis S, Joseph S, Koshy EP, Mathew B. Green synthesis and characterization of gold and silver nanoparticles using Mussaenda glabrata leaf extract and their environmental applications to dye degradation. Environ Sci Pollut Res. 2017;24(21):17347-17357. doi:10.1007/ s11356-017-9329-2

65. Dayem AA, Hossain MK, Lee $\mathrm{S}$, et al. The role of reactive oxygen species (ROS) in the biological activities of metallic nanoparticles. Int J Mol Sci. 2017;18:120. doi:10.3390/ijms18010120 


\section{Supplementary materials}

\section{UV-visible spectroscopy analysis}

Ultraviolet (UV)-visible absorption spectra of colloidal silver nanoparticles (AgNPs) (Figure S1) were obtained to demonstrate the reproducibility of the synthesis method used in this work and to determine the stability over time of the AuNP and Ag/AuNP samples (Figure S2).

\section{EDX analysis}

The chemical composition of individual alloyed bimetallic nanoparticles (NPs) was analyzed by EDX (Figure S3).

\section{SEM fixation study}

Scanning electron microscopy (SEM) images were completed for multidrug-resistant (MDR) E. coli (Figure S4A) and methicillin-resistant Staphylococcus aureus (MRSA) (Figure S4B) as controls to compare morphological changes with NP-treated samples.

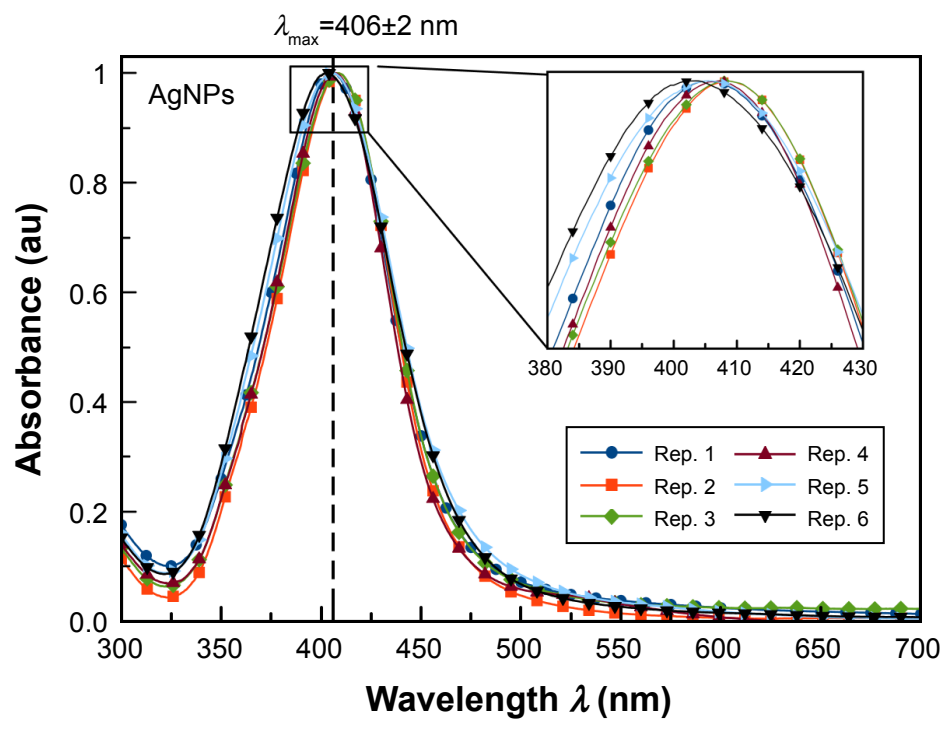

Figure SI Normalized UV-visible absorption spectra for colloidal AgNPs showing the average and SD for $\lambda_{\max }$. The AgNPs were synthesized by mixing $250 \mu \mathrm{L}$ of an aqueous solution $25 \mathrm{mM} \mathrm{AgNO}_{3}$ with $500 \mu \mathrm{L}$ of $1 \%$ starch solution at $\mathrm{pH}=1 \mathrm{I}$. The reaction time was set to 2 hours at $70^{\circ} \mathrm{C}$.

Abbreviations: AgNPs, silver nanoparticles; rep., repetition; UV, ultraviolet.
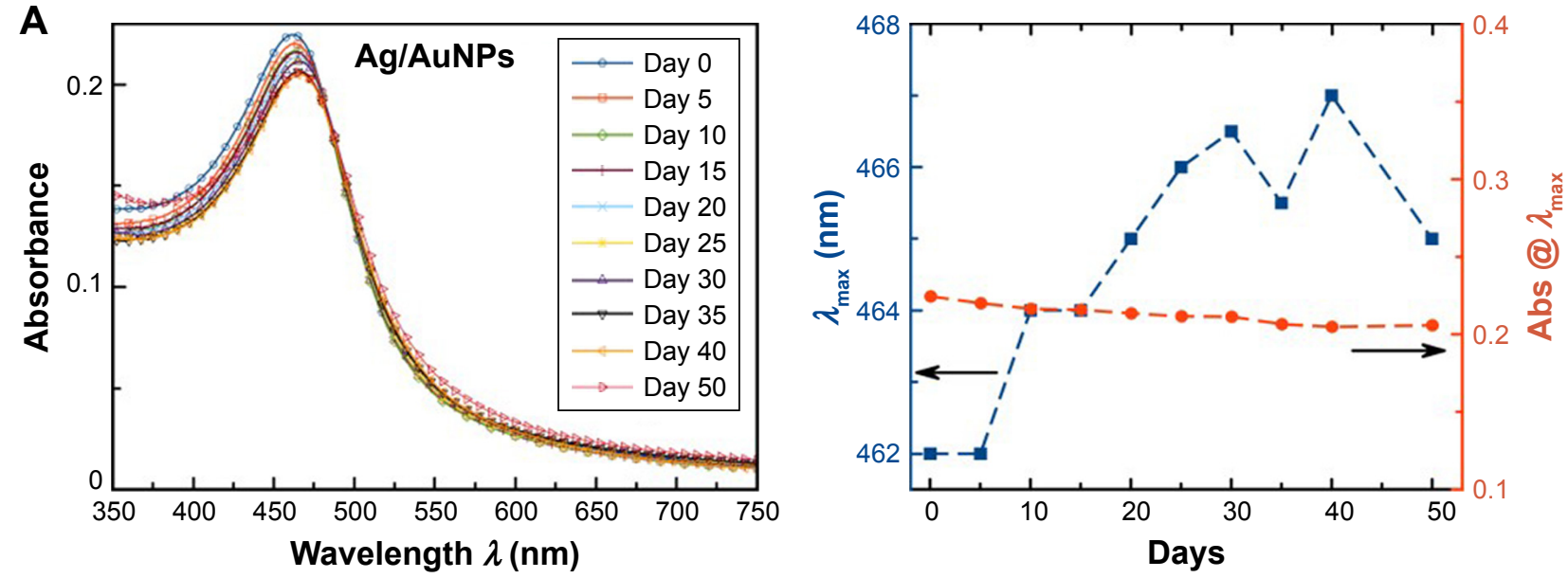

Figure S2 (Continued) 

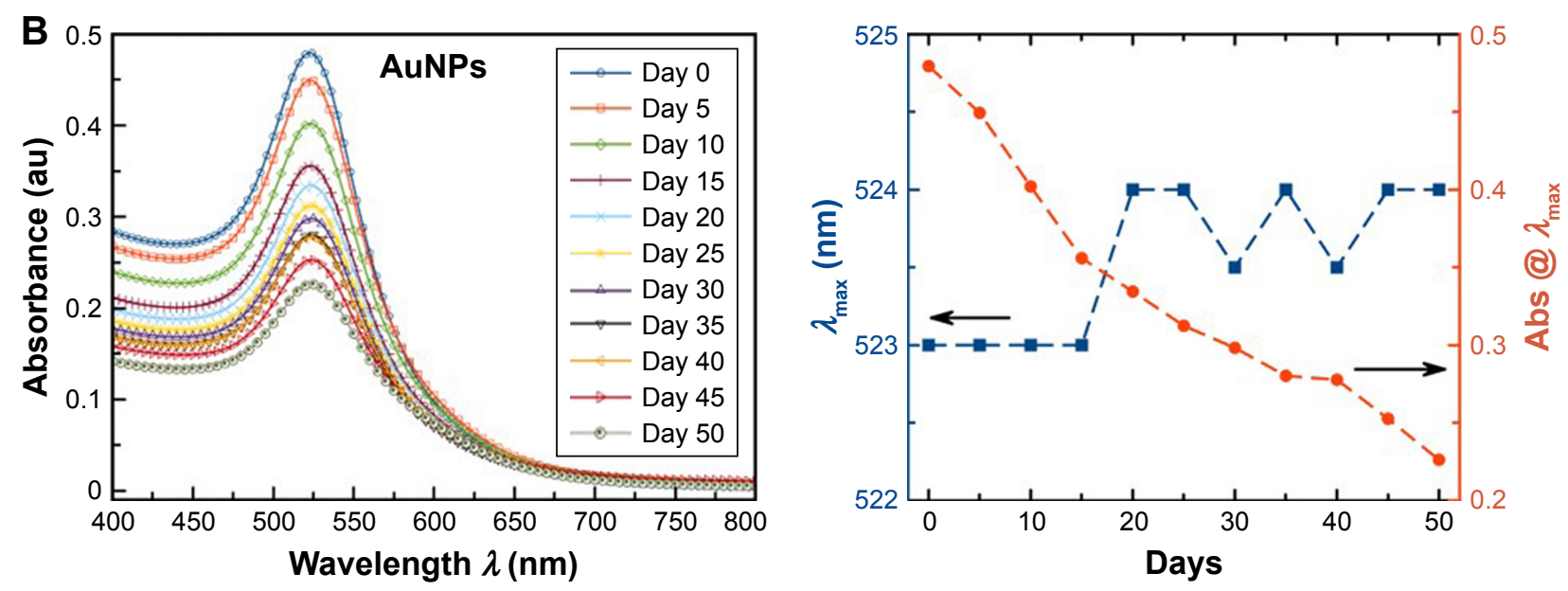

Figure S2 Non-normalized UV-visible absorption spectra (left figures) and shift of $\lambda_{\max }$ and absorbance at the given $\lambda_{\max }$ as a function of time (right figures) for colloidal (A) Ag/AuNPs and (B) AuNPs showing the stability of the samples over time.

Abbreviations: Abs@ $\lambda_{\max }$ absorbance at the corresponding $\lambda_{\max } ;$ AgNPs, silver nanoparticles; AuNPs, gold nanoparticles; UV, ultraviolet.
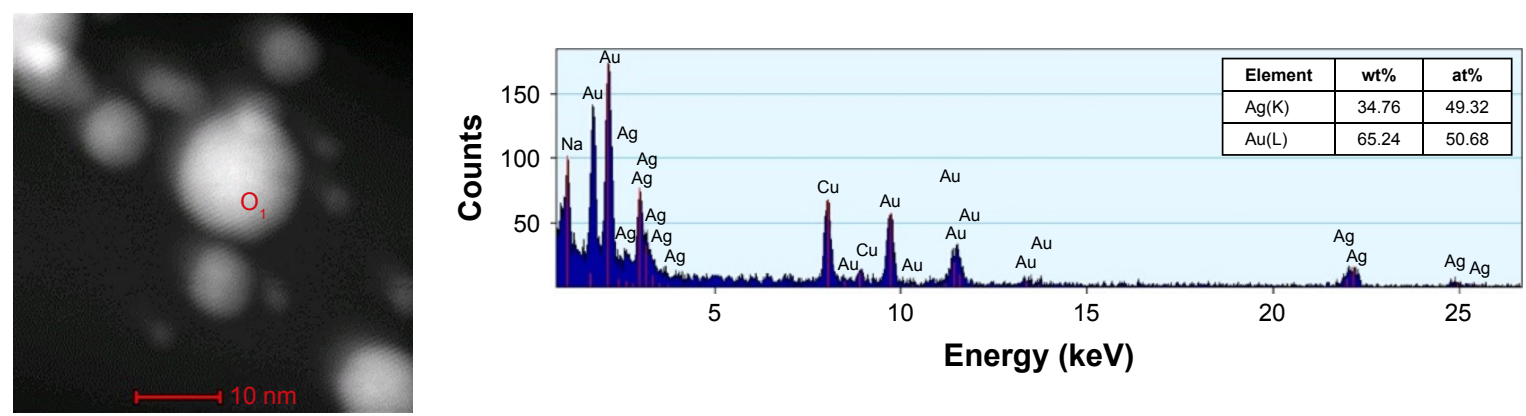

Figure S3 STEM image and EDS spectrum of the Ag/Au alloy NP marked with the point I in the STEM image. The Cu signal is due to the TEM grid. Abbreviations: at\%, atomic percentage; NPs, nanoparticles; STEM, scanning transmission electron microscopy; TEM, transmission electron microscopy.
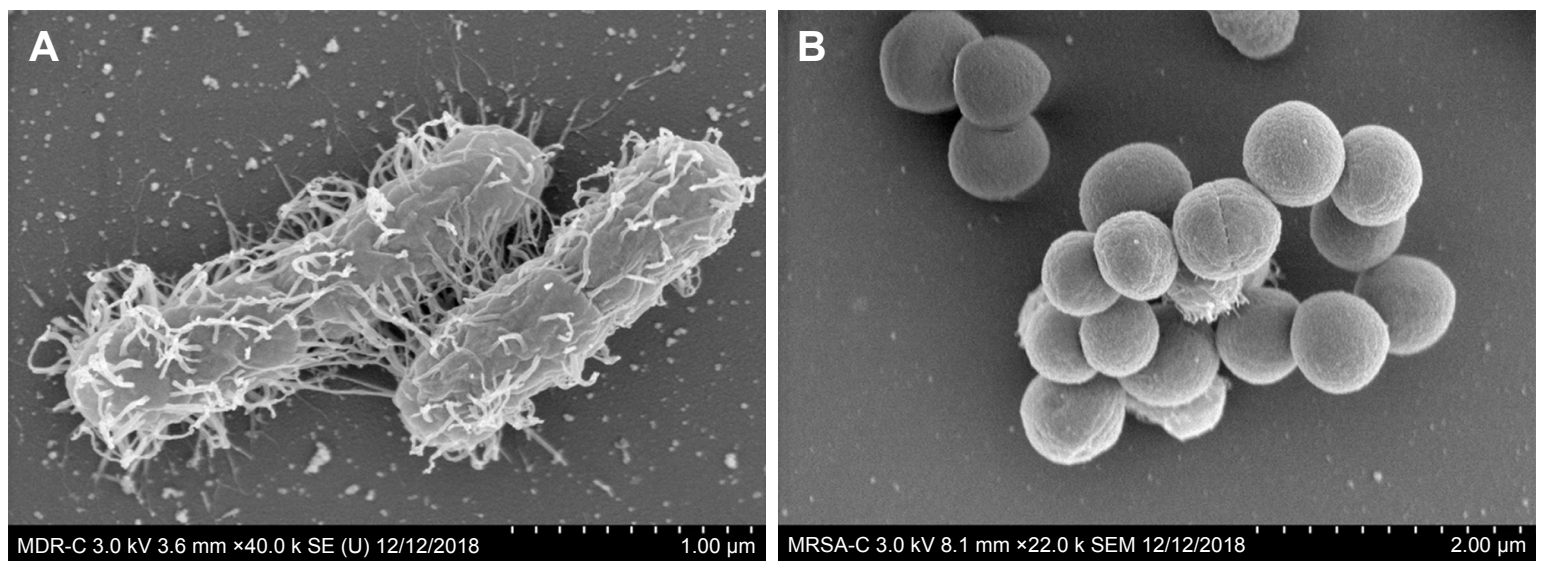

Figure S4 SEM images of untreated control samples of MDR E. coli (A) and MRSA (B).

Abbreviations: MDR E. coli, multidrug-resistant Escherichia coli; MRSA, methicillin-resistant Staphylococcus aureus; SEM, scanning electron microscopy. 


\section{Publish your work in this journal}

The International Journal of Nanomedicine is an international, peerreviewed journal focusing on the application of nanotechnology in diagnostics, therapeutics, and drug delivery systems throughout the biomedical field. This journal is indexed on PubMed Central, MedLine, CAS, SciSearch $\AA$, Current Contents $\AA /$ Clinical Medicine,

Journal Citation Reports/Science Edition, EMBase, Scopus and the Elsevier Bibliographic databases. The manuscript management system is completely online and includes a very quick and fair peer-review system, which is all easy to use. Visit http://www.dovepress.com/ testimonials.php to read real quotes from published authors.

Submit your manuscript here: http://www.dovepress.com/international-journal-of-nanomedicine-journal 